\title{
苯并咪唑基苂光化学传感器的合成与应用研究进展
}

\author{
吴彦城 ${ }^{a} \quad$ 嘉宜 $^{b}$ 关丽涛 ${ }^{c}$ 石 杰 ${ }^{a}$ \\ 曹 梁 ${ }^{a}$ 汪朝阳*, $a$ \\ ( ${ }^{a}$ 华南师范大学化学与环境学院 教育部环境理论化学重点实验室 广州 510006) \\ ( ${ }^{b}$ 广东药学院医药化工学院 中山 528458) \\ ( $c$ 华南农业大学材料与能源学院 广州 510642)
}

\begin{abstract}
摘要 苯并咪唑类化合物在多种有机溶剂和水溶液中能够发出特征荧光, 而且在一定条件下荧光性质会因多种因素而 发生改变, 因此其在苂光检测领域的应用受到了广泛的关注. 综述了苯并咪唑类传感器的合成及其在各种金属离子、 阴离子、无机物小分子、金属氧化物纳米粒子和有机小分子等物质检测中应用的新进展，并展望了苯并咪唑基荧光化 学传感器的发展趋势.
\end{abstract}

关键词 苯并咪唑; 传感器; 合成; 苂光检测; 进展

\section{Progress in the Synthesis and Application of Benzimidazole-Based Fluorescent Chemosensors}

\author{
Wu, Yancheng ${ }^{a} \quad$ You, Jiayi $^{b} \quad{\text { Guan, } \text { Litao }^{c} \quad \text { Shi, Jie }}^{a}$ \\ Cao, Liang ${ }^{a} \quad$ Wang, Zhaoyang ${ }^{*, a}$
}

( ${ }^{a}$ Key Laboratory of Theoretical Chemistry of Environment, Ministry of Education, School of Chemistry and Environment, South China Normal University, Guangzhou 510006)

( ${ }^{b}$ School of Chemistry and Chemical Engineering, Guangdong Pharmaceutical University, Zhongshan 548528)

( ${ }^{c}$ College of Materials and Energy, South China Agricultural University, Guangzhou 510642)

\begin{abstract}
Many benzimidazole compounds can emit characteristic fluorescence in various organic solvents and aqueous solutions, and their fluorescence properties can be influenced by some factors under certain conditions, which make them used in the field of fluorescence detection. Recently, more and more attention has been attached to the benzimidazole-based fluorescent chemosensors. Their synthesis and the extensive application in the detection of metal ions, anions, inorganic small molecules, metal oxide nanoparticles, organic small molecules, and so on are reviewed. The development trend of benzimidazole-based fluorescent chemosensors is prospected.
\end{abstract}

Keywords benzimidazole; sensor; synthesis; fluorescence detection; progress

苯并咪唑类化合物广泛应用于药物化学、生物化学 等领域 ${ }^{[1 \sim 6]}$, 近年来在阻燃材料、配位化学、液晶材料 等方面也得到应用 ${ }^{[5 \sim 10]}$, 这些方面已有一些综述报道其 研究进展. 事实上, 作为同时含有两个氮原子的杂环, 苯并咪唑类化合物可通过分子内质子转移, 发射出荧光 量子产率高的特征荧光, 也容易与金属离子形成配合 物, 且其结构中的 NH 易与阴离子形成氢键, 这些因素
均可导致苂光性质的改变, 使其在苂光检测领域也有着 广泛的应用. 鉴于此, 本文综述了苯并咪唑基荧光化学 传感器的合成与其在检测领域应用的新进展.

\section{1 应用于金属阳离子的检测}

金属离子对自然环境和生物生长有着重大影响, 因 此近年来环境和生物体中金属离子的检测受到了很大

*E-mail: wangzy@scnu.edu.cn

Received July 20, 2015; revised August 21, 2015; published online August 31, 2015.

Project supported by the Natural Science Foundation of Guangdong Province (No. 2014A030313429), the 3rd Talents Special Funds of Guangdong Higher Education (No. Guangdong-Finance-Education [2011]431) and the National Natural Science Foundation of China (No. 31200439).

广东省自然科学基金(No. 2014A030313429)、广东省高等学校人才引进专项资金(No. 粤财教[2011]431 号)、国家自然科学基金(No. 31200439)资助项 目. 
的关注. 其中, 有很多文献报道了基于苯并咪唑化合物 的荧光化学传感器用于检测 $\mathrm{Hg}^{2+} 、 \mathrm{Fe}^{3+} 、 \mathrm{Cu}^{2+} 、 \mathrm{Zn}^{2+}$ 、 $\mathrm{Al}^{3+}$ 等金属离子.

\section{1 应用于录离子的检测}

作为污染性强的重金属离子, $\mathrm{Hg}^{2+}$ 的检测一直备受 关注, 在苯并咪唑基苂光化学传感器中报道最多. 例如, Tzeng 等 ${ }^{[11]}$ 报道了 2-(2'-吡啶基)苯并咪唑(1)(图 1)与金属 铼配位而应用于 $\mathrm{Hg}^{2+}$ 检测的传感器.
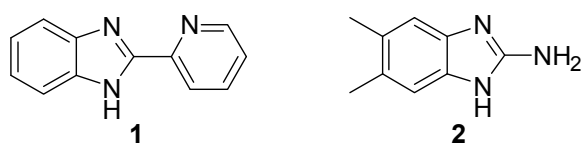

图 1 用于检测采离子苂光化学传感器中的一些苯并咪唑配 体或结构单元

Figure 1 Some benzimidazole compounds as ligand or basic unit in fluorescent chemosensors for $\mathrm{Hg}^{2+}$ detection

罗丹明是常用于设计成荧光探针的荧光基团, 引进 苯并咪唑基能够明显提高其荧光性能且能增加其对金 属离子的选择性检测. 例如, 将苯并咪唑分子 2 (Figure 1)通过 $C=N$ 键引进到罗丹明 $6 \mathrm{G}$ 中, 可设计出用于检测 $\mathrm{Hg}^{2+}$ 的 “turn-on” 型比色化学传感器, 在其乙腈溶液中, $\mathrm{Hg}^{2+}$ 的加入能够使荧光显著增强. 不仅如此, 加入 $\mathrm{Hg}^{2+}$ 后, 溶液的颜色由肉眼就能看出从无色变为淡粉色, 而 苂光的颜色由无色变为绿色 ${ }^{[12]}$.

近来, 也有将喹啉苂光团与苯并咪唑荧光团连接起 来而设计、合成用于检测 $\mathrm{Hg}^{2+}$ 的化学传感器的报道. 例 如, 汤立军课题组 ${ }^{[13]}$ 以 2-甲基-8-羟基喹啉(3)为原料, 为改善目标分子 4 的水溶性, 先引入了二乙二醇单甲醚, 再利用醛基与邻苯二胺缩合反应而引进苯并咪唑基 (Scheme 1), 得到的化学传感器 4 在 $475 \mathrm{~nm}$ 处有强的苂 光发射峰, 苂光量子产率达 0.37 . 加入 $\mathrm{Hg}^{2+}$ 后, 目标分 子 4 喹啉环上 $\mathrm{N}$ 原子以及苯并咪唑环上亚胺 $\mathrm{N}$ 原子共

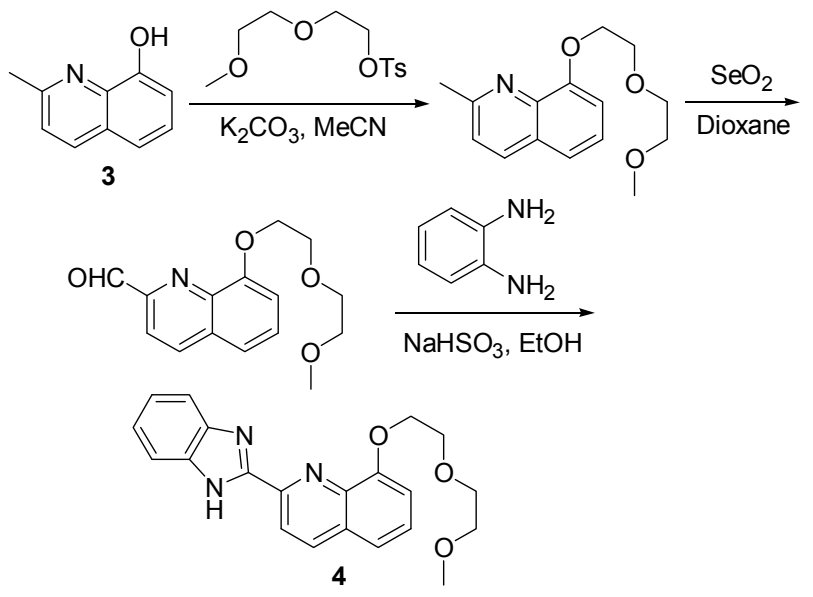

图式 1 传感器 4 的合成 Scheme 1 Synthesis of sensor 4
同与 $\mathrm{Hg}^{2+}$ 发生 1:1 的络合, 电荷从激发态的 4 转移到 $\mathrm{Hg}^{2+}$ 上, 导致 4 的苂光发生猝灭, 而其他离子不受影响, 从而实现了 $\mathrm{Hg}^{2+}$ 的选择性检测.

其实, 如果不先引入二乙二醇单甲醚，也可获得喹 啉苂光团与苯并咪唑苂光团连接的 $\mathrm{Hg}^{2+}$ 检测的化学传 感器(Eq. 1). 在 5 的 $\mathrm{H}_{2} \mathrm{O} / \mathrm{DMSO}$ 溶液中, 加入的 $\mathrm{Hg}^{2+}$ 与 5 发生 1: 1 络合, 使传感器 5 的苂光猝灭, 且溶液颜色 在紫外灯下由蓝色变为无色. 5 能在 $\mathrm{pH}$ 为 $2.0 \sim 11.0$ 的 范围内工作，对 $\mathrm{Hg}^{2+}$ 检测下限达 $9.56 \times 10^{-9} \mathrm{~mol} / \mathrm{L}$. 不 仅能在溶液中检测 $\mathrm{Hg}^{2+}$, 而且可用经 5 的 $\mathrm{H}_{2} \mathrm{O} / \mathrm{DMSO}$ 溶液浸泡过的试纸在紫外灯下通过颜色的变化来实现 $\mathrm{Hg}^{2+}$ 的检测 ${ }^{[14]}$.

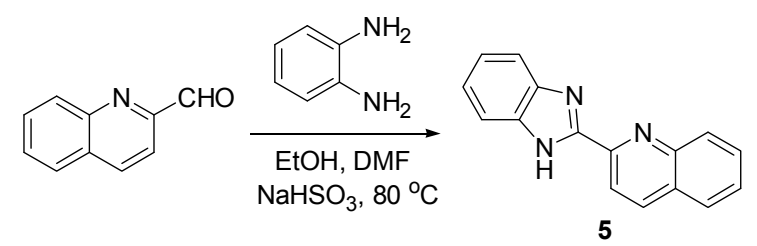

将给电子体三苯胺与苯并咪唑苂光基团相连，也是 设计检测 $\mathrm{Hg}^{2+}$ 的化学传感器的一种手段. 例如, $\mathrm{Li}$ 等 ${ }^{[15]}$ 将 4-二苯胺苯甲醛与邻苯二胺在甲醇溶液中缩合, 可得 化学传感器 6 (Eq. 2). 化合物 6 在乙腈溶液中分别与 $\mathrm{Hg}^{2+}$ 和 $\mathrm{Fe}^{3+}$ 络合, 紫外吸收波长发生蓝移, 而且苂光猝 灭使溶液颜色有明显变化. 这是 $\mathbf{6}$ 与 $\mathrm{Hg}^{2+}$ 和 $\mathrm{Fe}^{3+}$ 络合影 响的分子内电荷转移(ICT)过程所导致的颜色改变, 但 传感器 6 对 $\mathrm{Fe}^{3+}$ 的灵敏度优于对 $\mathrm{Hg}^{2+}$ 的.<smiles>O=Cc1ccc(N(c2ccccc2)c2ccccc2)cc1</smiles><smiles></smiles><smiles>c1ccc(N(c2ccccc2)c2ccc(-c3nc4ccccc4[nH]3)cc2)cc1</smiles>

基于廉价氨基酸合成苯并咪唑近年来引人注 目 $^{[5,16,17]}$, 利用手性氨基酸构建苯并咪唑类苂光化学传 感器也有相关文献报道. 例如 Ghosh 等 ${ }^{[18]}$ 利用 $L$-倾氨酸 衍生物 7 与邻苯二胺反应，再进一步以 5-辛氧基间二苯 甲酰氯进行连接, 设计合成了含有两个苯并咪唑苂光团 的 $\mathrm{Hg}^{2+}$ 检测化学传感器 8 (Scheme 2). 也可用无手性的 甘氨酸合成 8 的类似物, 但其对 $\mathrm{Hg}^{2+}$ 的检测无选择性.

目前, 国内外大多数对于 $\mathrm{Hg}^{2+}$ 的检测只是体外检 测, 而生物体内的检测鲜见报道. 但 2013 年 Chowdhury 等 ${ }^{[19]}$ 在这方面做了重要突破, 他们将苯并咪唑基团键 入氟嗍二吡咯类苂光分子中, 利用其摩尔吸光系数较 高、苂光光谱峰窄而尖锐、光学性质稳定等特点, 得到 了可用于体内外检测 $\mathrm{Hg}^{2+}$ 的荧光增强型传感器 9 (Scheme 3), 能实现对人类乳腺癌细胞中 $\mathrm{Hg}^{2+}$ 的检测. 


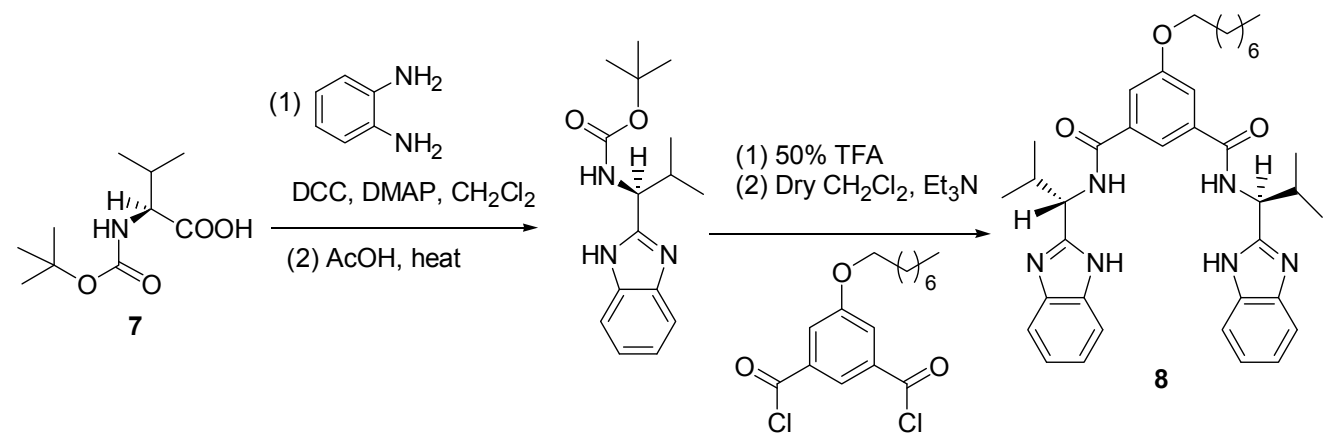

图式 2 传感器 8 的合成

Scheme 2 Synthesis of sensor 8<smiles>Cc1ccc(C(c2ccc(C=O)[nH]2)c2ccc(C=O)[nH]2)cc1</smiles>

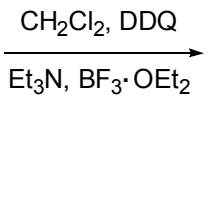<smiles>COC(=O)c1ccc2n1P(F)P(F)N1C(c3nc4ccccc4[nH]3)=CC=C2C1c1ccc(C)cc1</smiles>

9

图式 3 传感器 9 的合成

Scheme 3 Synthesis of sensor 9

\section{2 应用于铁离子的检测}

利用含有苯并咪唑基的荧光探针高效检测 $\mathrm{Fe}^{3+}$ 、 $\mathrm{Cu}^{2+}$ 等金属离子, 也是一直倍受关注的热点 ${ }^{[20 ~ 23]}$. 基于 罗丹明荧光基团的 “turn-on” 型苂光探针设计，可应用 于 $\mathrm{Fe}^{3+}$ 的选择性检测. 例如, Pan 等 ${ }^{[24]}$ 利用邻苯二胺与 羟基乙酸缩合, 经氧化制备出苯并咪唑化合物 $\mathbf{1 0}$ 后, 将 其引进到罗丹明 $\mathrm{B}$ 酰肼 $\mathbf{1 1}$ 中, 设计、合成了荧光探针 12 (Scheme 4), 其在乙腈溶液中 $580 \mathrm{~nm}$ 处有很弱苂光. 但是, 当加入 10 equiv. $\mathrm{Fe}^{3+}$ 后, 12 的苂光红移至 $582 \mathrm{~nm}$ 并荧光显著增强, 增强倍数达 1098 倍. 当 $\mathrm{Fe}^{3+}$ 与其他金 属离子共存时, 除了 $\mathrm{Cu}^{2+}$ 能够使其苂光稍微减弱外, 其
他金属离子无影响，且该选择性检测对 $\mathrm{Fe}^{3+}$ 的检测下限 为 $1.5 \times 10^{-8} \mathrm{~mol} / \mathrm{L}$.

由于丹磺酰基强的苂光性能，其经常被设计于检测 金属离子的化学传感器中, 近年来也有将丹磺酰基与苯 并咪唑连接起来而设计用于检测 $\mathrm{Fe}^{3+}$ 的荧光探针文献 报道. 例如，张勇等 ${ }^{[25]}$ 利用 $N$-甲基邻苯二胺与亚氨基二 乙酸的缩合反应, 制得了二苯并咪唑类化合物 13, 进一 步引进丹磺酰基后合成了荧光探针 $\mathbf{1 4}$ (Scheme 5), 其在 $\mathrm{H}_{2} \mathrm{O} / \mathrm{DMSO}$ 溶液中能够与 $\mathrm{Fe}^{3+}$ 生成 $1: 1$ 的配合物, 探 针 14 的苂光随着 $\mathrm{Fe}^{3+}$ 的加入而逐渐猝灭, 能实现对 $\mathrm{Fe}^{3+}$ 的选择性检测.

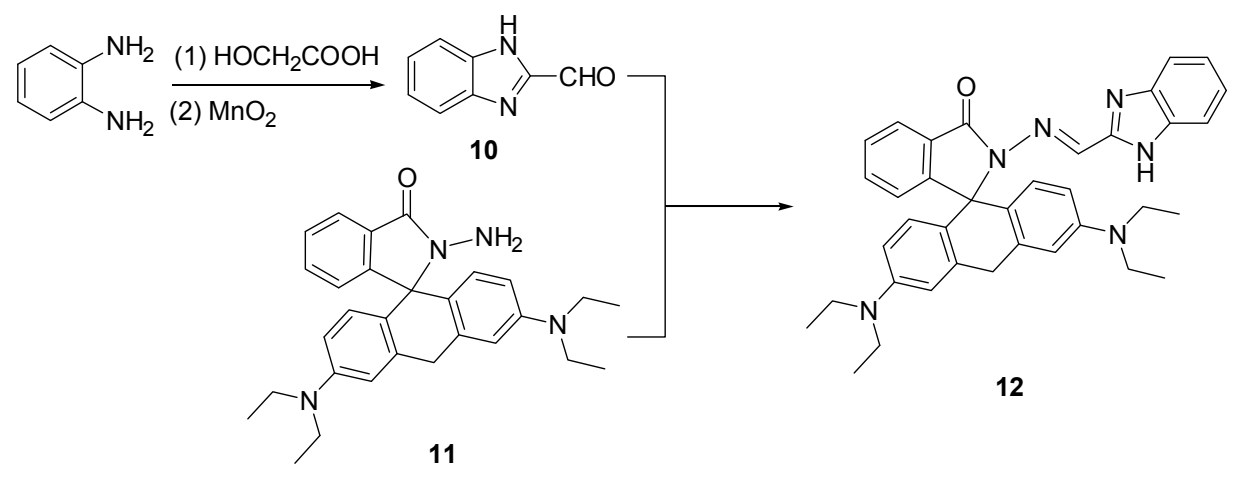

图式 4 荧光探针 12 的合成

Scheme 4 Synthesis of fluorescent probe $\mathbf{1 2}$ 

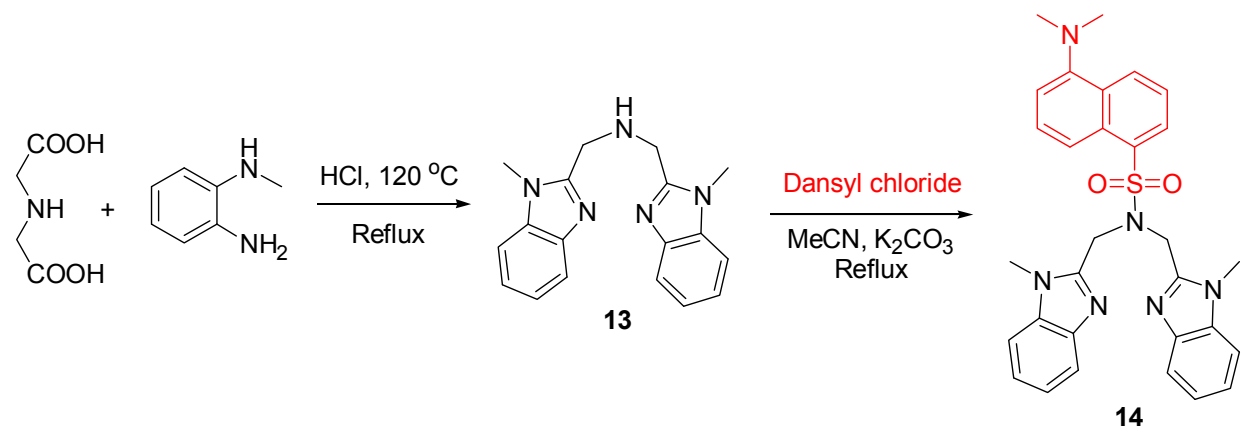

图式 5 苂光探针 14 的合成

Scheme 5 Synthesis of fluorescent probe $\mathbf{1 4}$

从设计简单的角度看, 无需其他荧光基团协助的纯 苯并咪唑类苂光化学传感器更值得关注. 2014 年, Wei 等 ${ }^{[26]}$ 利用邻苯二胺和草酸在多聚磷酸(PPA)作用下反应 生成联二苯并咪唑中间体 $\mathbf{1 5}$, 然后引进氰基以增加其与 金属离子络合位点, 从而设计合成了化学传感器 16 (Scheme 6). 在 $\mathrm{H}_{2} \mathrm{O} / \mathrm{DMSO}$ 溶液中, 16 能与 $\mathrm{Fe}^{3+}$ 形成 1 : 2 配合物, 荧光发生猝灭, 且在紫外灯下可观察到溶液 颜色由淡蓝色变为无色, 而其他离子无此现象. 不仅如 此, 在该溶液中继续加入 $\mathrm{H}_{2} \mathrm{PO}_{4}^{-}$时, 由于磷酸铁沉淀的 生成, $\mathrm{Fe}^{3+}$ 能够从配合物中解离出来, 使 $\mathbf{1 6}$ 的荧光恢复, 而其他阴离子则几乎没有影响. 因此, 该设计能成功地 得到用于连续检测 $\mathrm{Fe}^{3+}$ 和 $\mathrm{H}_{2} \mathrm{PO}_{4}^{-}$的 “on-off-on” 型传 感器.
将苯并咪唑荧光团引进到对 (二苯乙炔基)苯中，也 可设计合成用于检测 $\mathrm{Fe}^{3+}$ 的苂光传感器. 例如, 2013 年 $\mathrm{Wu}$ 等 ${ }^{[27]}$ 从苯的溴代衍生物 17 开始, 通过连续引入苯并 咪唑荧光团和苯乙炔基，设计合成了检测 $\mathrm{Fe}^{3+}$ 的比率型 传感器 18 (Scheme 7). 在 $\mathrm{H}_{2} \mathrm{O} / \mathrm{DMSO}$ 溶液中, 随着 $\mathrm{Fe}^{3+}$ 的加入, 18 的紫外吸收明显增强, 原来 $433 \mathrm{~nm}$ 处的 苂光逐渐猝灭, 并在 $380 \mathrm{~nm}$ 处产生一个新的苂光发射 峰. 虽然 $\mathrm{Cr}^{3+}$ 对 18 的苂光光谱有类似影响, 但是并不改 变其紫外吸收光谱, 故 18 可分别实现 $\mathrm{Fe}^{3+}$ 和 $\mathrm{Cr}^{3+}$ 的选 择性检测, 检测下限分别为 2 和 $25 \mu \mathrm{mol} / \mathrm{L}$.

2-(2'-氨基苯基)-苯并咪唑(19)也具有多个 $\mathrm{N}$ 原子络 合位点, 故利用 19 设计荧光探针的报道较多, 特别是 Jang 课题组. 2008 年他们 ${ }^{[28]}$ 利用间苯二甲醛通过 $\mathrm{C}=\mathrm{N}$

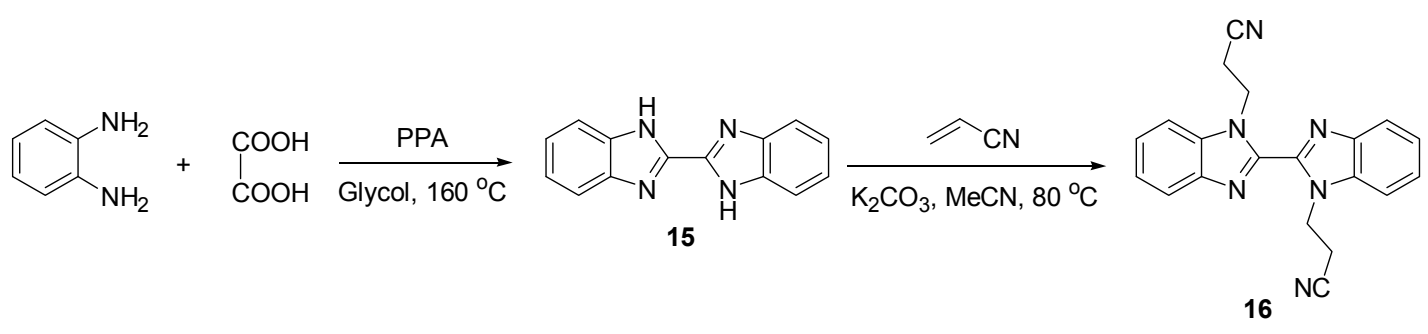

图式 6 传感器 16 的合成

Scheme 6 Synthesis of sensor 16<smiles>BrCc1c(Br)ccc(Br)c1CBr</smiles>

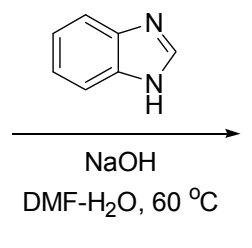

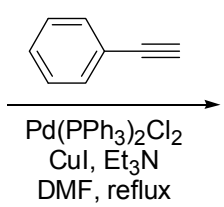<smiles>C(#Cc1ccc(C#Cc2ccccc2)c(Cn2cnc3ccccc32)c1Cn1cnc2ccccc21)c1ccccc1</smiles>

图式 7 传感器 $\mathbf{1 8}$ 的合成

Scheme 7 Synthesis of sensor $\mathbf{1 8}$ 
键将 2 个 19 分子连接起来, 设计合成了含有多个 $\mathrm{sp}^{2}$ 杂 化氮原子的 $\mathrm{Fe}^{3+}$ 比率型荧光探针 20 (Eq. 3). 在 $\mathrm{CH}_{3} \mathrm{CN} / \mathrm{H}_{2} \mathrm{O}$ 溶液中, 加入 $\mathrm{Fe}^{3+}$ 离子后, 苂光探针 20 原 来在 $412 \mathrm{~nm}$ 处的强苂光吸收减弱, 在 $475 \mathrm{~nm}$ 处产生新 的荧光发射峰，而其他金属离子则对其苂光几乎没有影 响.<smiles>Cc1ccc2[nH]c(-c3ccc(CO[C+]c4cccc(C=O)c4)cc3)nc2c1</smiles><smiles>C(=N/c1ccccc1/C=N/c1ccccc1-c1nc2ccccc2[nH]1)\c1ccccc1</smiles>

19

2010 年, Jang 等 ${ }^{[29]}$ 将 2-(2'-氨基苯基)-苯并咪唑(19) 与具有三个醛基的化合物 21 进行缩合, 再用 $\mathrm{NaBH}_{4}$
还原，生成了可用于同时检测 $\mathrm{Fe}^{3+}$ 和 $\mathrm{Cu}^{2+}$ 的苂光探针 22 (Scheme 8). 值得注意的是，化合物 21 是一种 “三脚 架” 原料，此类分子反应后所得的三脚架化合物具有三 个灵活的、可与金属离子配位的侧链，使其应用于生物 医药、苂光检测等方面有独特的优越性 ${ }^{[30]}$. 苂光探针 22 在实际应用中, 也的确如此 ${ }^{[29]}$.

如果将三脚架原料 21 中的一个苯甲醛侧链更换为 葱基荧光团, 即以三脚架分子 24 代替 Scheme 8 的卤代 烃 23 为原料进行系列合成, 可得到新的同时含有葱和 苯并咪唑的双荧光团 $\mathrm{Fe}^{3+}$ 比率型化学传感器 $\mathbf{2 5}$ (Scheme $9)^{[31]}$.

类似地，以苯环为中心核的三脚架卤代烃化合物 $\mathbf{2 6}$ 为原料, 也可通过多步反应引进苯并咪唑而合成化学传 感器 27 (Scheme 10). 在化合物 $\mathbf{2 6}$ 中, 由于邻位基团的 空间排斥作用，相邻基团处于苯环平面的两侧，这使得 传感器 27 上的苯并咪唑基团均处于中心核苯环的同一 侧，从而有利于苯并咪唑基荧光团相互堆积，导致化合 物 27 在 $\mathrm{CH}_{3} \mathrm{CN} / \mathrm{H}_{2} \mathrm{O}$ 溶液中于 418 和 $580 \mathrm{~nm}$ 处出现两 个苂光发射峰. 加入各种金属离子后, $\mathrm{Fe}^{3+}$ 和 $\mathrm{Cu}^{2+}$ 能够

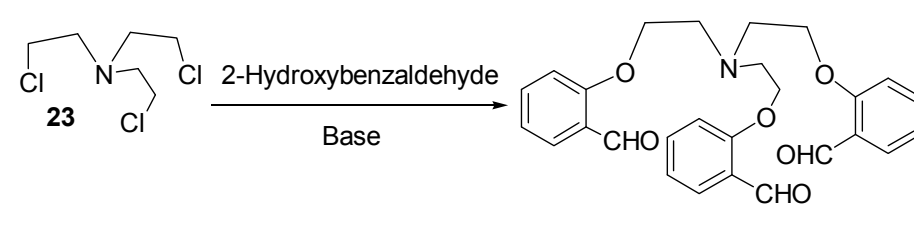

21<smiles>[B]=C1Nc2ccccc2N1</smiles>

图式 8 苂光探针 22 的合成

Scheme 8 Synthesis of fluorescent probe 22
(1) $19, \mathrm{Zn}\left(\mathrm{ClO}_{4}\right)_{2}$ (2) $\mathrm{NaBH}_{4}$, reflux<smiles>[B]c1ccccc1NCc1ccccc1OCCN1CCOc2ccccc2CNc2ccccc2OCC1</smiles>

22

(1) $19, \mathrm{Zn}\left(\mathrm{ClO}_{4}\right)_{2}, \mathrm{MeOH} / \mathrm{THF}$

(2) $\mathrm{NaBH}_{4}, \mathrm{THF}$, reflux

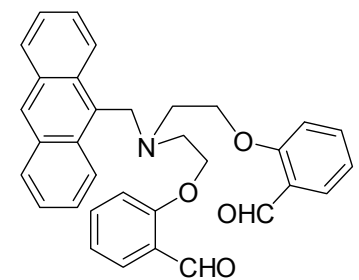

24<smiles>O=Cc1ccccc1O</smiles>

$\underset{\text { Reflux }}{\stackrel{\mathrm{KOH} \text {, Propanol }}{\longrightarrow}}$

$\mathrm{Cl}$

4

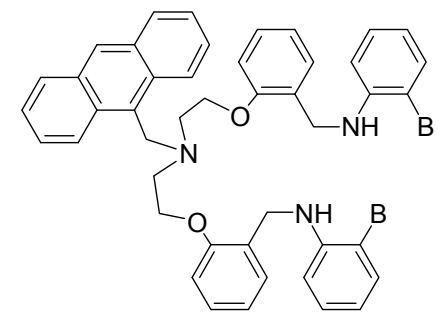

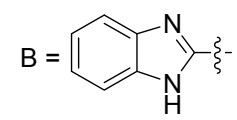

25

图式 9 化学传感器 25 的合成

Scheme 9 Synthesis of sensor 25 


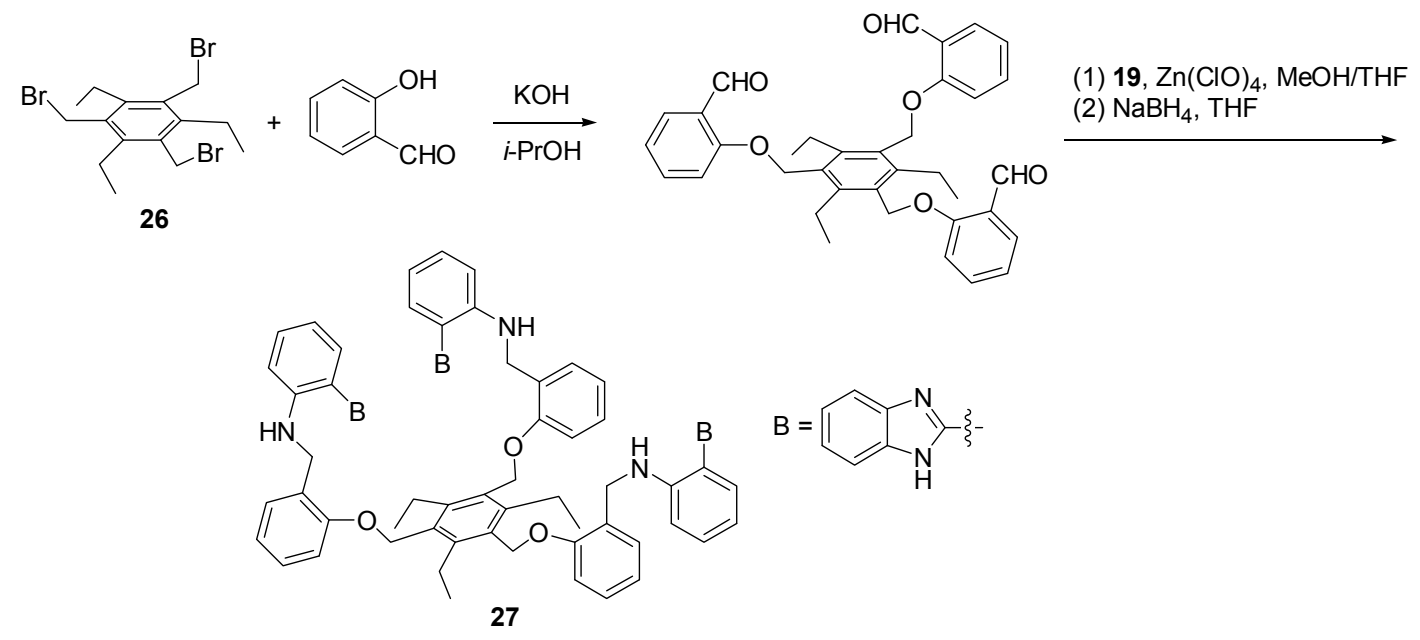

图式 10 传感器 $\mathbf{2 7}$ 的合成

Scheme 10 Synthesis of sensor 27

使其荧光发射峰发生很明显的变化: 随着 $\mathrm{Fe}^{3+}$ 的加入, 传感器 27 在 $418 \mathrm{~nm}$ 处苂光发生猝灭, 在 $462 \mathrm{~nm}$ 处产生 了新的荧光发射峰; 随着 $\mathrm{Cu}^{2+}$ 的加入, 化合物 $\mathbf{2 7}$ 在 580 $\mathrm{nm}$ 处荧光发生猝灭, 而 $418 \mathrm{~nm}$ 处苂光增强. 因此, 化 学传感器 27 能够同时检测 $\mathrm{Fe}^{3+}$ 和 $\mathrm{Cu}^{2+[32]}$.

\section{3 应用于铜离子的检测}

即使只含有一个醛基的喹啉类化合物, 也可用于同 2-(2'-氨基苯基)-苯并咪唑(19)缩合而设计出苂光探针. 2013 年, 汤立军课题组 ${ }^{[33]}$ 利用这种策略将喹啉荧光团 引进到苯并咪唑基苂光探针 28 中(Eq. 4). 在 $\mathrm{EtOH} / \mathrm{H}_{2} \mathrm{O}$ 中, 探针 28 在 $423 \mathrm{~nm}$ 处有微弱的苂光发射峰, 加入 $\mathrm{Cu}^{2+}$ 后, 探针 28 与 $\mathrm{Cu}^{2+}$ 以化学计量比 $2: 1$ 发生络合, 络合常数为 $2.16 \times 10^{5} \mathrm{~L}^{2} \cdot \mathrm{mol}^{-2}$, 使该处的荧光明显增 强, 而其他金属离子无影响. 进一步在 $28-\mathrm{Cu}^{2+}$ 复合体 溶液中加入不同的阴离子, 发现当加入 $\mathrm{CN}^{-}$时, 苂光光 谱最大发射峰从 $423 \mathrm{~nm}$ 处蓝移到 $419 \mathrm{~nm}$ 处, 苂光再次 增强, 而其他离子则无此现象. 因此, 该 “turn-on” 型苂 光探针也能够很好地选择性检测 $\mathrm{CN}^{-}$.

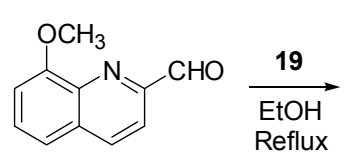<smiles>COc1cccc2ccc(C3Nc4ccccc4-c4nc5ccccc5n43)nc12</smiles>

28
类似地, 只含有一个醛基的邻菜二酚类化合物, 也 可用于同 2-(2'-氨基苯基)-苯并咪唑(19)缩合而设计出荧 光探针, 如汤立军课题组 ${ }^{[34]}$ 报道的苂光探针 29 (Eq. 5). 在 $\mathrm{CH}_{3} \mathrm{OH} / \mathrm{H}_{2} \mathrm{O}$ 溶液中, 不同的 $\mathrm{pH}$ 值对探针 $\mathbf{2 9}$ 的苂光 性能有很大的影响, 在 $\mathrm{pH}=7$ 时其荧光性能最好. 向探 针 29 的溶液加入 1 equiv. 的不同金属离子, 探针 29 的苂
光能够被 $\mathrm{Cu}^{2+}$ 猝灭, 而其他离子无影响. 探针 29 与 $\mathrm{Cu}^{2+}$ 以 $1: 1$ 络合, 络合常数为 $7.38 \times 10^{6} \mathrm{~L} / \mathrm{mol}$. 再进一 步研究表明, 在 $29-\mathrm{Cu}^{2+}$ 复合体溶液中加入各种阴离子, 只有 $\mathrm{CN}^{-}$能够使其荧光显著增强. 这是由于 $\mathrm{CN}^{-}$的加 入, 使得 $\mathrm{Cu}^{2+}$ 与 $\mathrm{CN}^{-}$结合形成 $\left[\mathrm{Cu}(\mathrm{CN})_{x}\right]^{n-}$ 而离开荧光 探针 29. 对 $\mathrm{CN}^{-}$检测下限达 $1.86 \times 10^{-5} \mathrm{~mol} / \mathrm{L}$, 远低于 世界卫生组织制定的饮用水的 $\mathrm{CN}^{-}$的含量的最高浓度 $(19 \mu \mathrm{mol} / \mathrm{L})$.<smiles>O=Cc1cc2ccccc2c(-c2c(O)ccc3ccccc23)c1O</smiles>

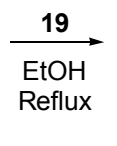<smiles>Oc1ccc2ccccc2c1-c1c(O)c(C2Nc3ccccc3-c3nc4ccccc4n32)cc2ccccc12</smiles>

其实, 简单的小分子吡咯甲醛也能与 2-(2'-氨基苯 基)-苯并咪唑(19)缩合而构建苂光探针, 如 Singh 等 ${ }^{[35]}$ 报道的传感器 30 (Eq. 6). 在 $\mathrm{CH}_{3} \mathrm{CN} / \mathrm{H}_{2} \mathrm{O}$ 溶液中, 传感 器 30 对 $\mathrm{Cu}^{2+}$ 有高灵敏性和选择性, 这主要是 30 与 $\mathrm{Cu}^{2+}$ 以 $1: 1$ 发生络合而导致荧光猝灭, 络合常数为 $5.34 \times 10^{3} \mathrm{~L} / \mathrm{mol}$, 检测下限达 $0.98 \mu \mathrm{mol} / \mathrm{L}$. 不仅如此, 在 $30-\mathrm{Cu}^{2+}$ 复合体溶液中, 加入 $\mathrm{PO}_{4}^{3-}$ 能够使 $\mathrm{Cu}^{2+}$ 从复 合体中脱离出来而导致传感器 $\mathbf{3 0}$ 的荧光恢复, 而其他 阴离子则无此现象, 对 $\mathrm{PO}_{4}^{3-}$ 的检测下限达 $2.8 \mu \mathrm{mol} / \mathrm{L}$.

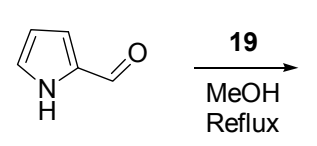

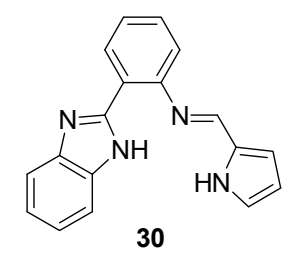


同样地，含有一个醛基的酚类化合物 31 也可通过 $\mathrm{C}=\mathrm{N}$ 键与 2-( $2^{\prime}$-氨基苯基)-苯并咪唑(19)相连, 构建用 于检测 $\mathrm{Cu}^{2+}$ 的化学传感器 32 (Eq. 7). 在 $\mathrm{CH}_{3} \mathrm{CN} / \mathrm{H}_{2} \mathrm{O}$ 溶 液中, $\mathrm{Cu}^{2+}$ 的加入使 32 在 $429 \mathrm{~nm}$ 处的苂光发生猝灭, 在 紫外灯下溶液颜色由深蓝色变为灰色, 检测下限达 1.82 $\times 10^{-8} \mathrm{~mol} / \mathrm{L}$. 在 $32-\mathrm{Cu}^{2+}$ 复合体溶液中继续加入 $\mathrm{CN}^{-}$ 后 32 的苂光恢复, 这是由于 $\mathrm{CN}^{-}$的加入使得 $\mathrm{Cu}^{2+}$ 从复 合体中脱离出来, 所以 $32-\mathrm{Cu}^{2+}$ 复合体能够实现 $\mathrm{CN}^{-}$的 选择性检测，检测下限达 $1.62 \times 10^{-6} \mathrm{~mol} / \mathrm{L}^{[36]}$.<smiles>Cc1cc(C=O)c(O)c(CO)c1</smiles>

31

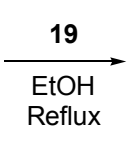

Reflux

$\mathrm{HO}$

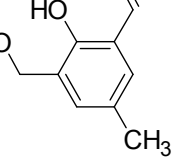

32
最近, Duan 等 ${ }^{[37]}$ 将苯并咪唑引进到苯甲醛的对位 上, 先合成了含有一个醛基的化合物 33 , 再通过 $\mathrm{C}=\mathrm{N}$ 键与对苯二胺相连, 也构建了用于检测 $\mathrm{Cu}^{2+}$ 的化学传感 器 34 (Scheme 11). 在 34 的 DMF 溶液中, 加入的 $\mathrm{Cu}^{2+}$ 能与 34 发生络合而形成一个刚性结构, 导致 34 的紫外 吸收和荧光增强，而其他离子则几乎无影响，从而实现 了 $\mathrm{Cu}^{2+}$ 的选择性检测, 检测下限达 $1 \times 10^{-9} \mathrm{~mol} / \mathrm{L}$.

近来, 汤立军课题组 ${ }^{[38]}$ 在 2 -(2'-氨基苯基)-苯并咪 唑(19)上先引进氯乙酰基得到化合物 35 , 乙酰基能增强 其 $2^{\prime}-\mathrm{NH}$ 的酸性, 有利于发生激发态分子内质子转移 (ESIPT); 再引进亲水性的 $N$-(2-羟乙基)哌嗪增加其水溶
性，成功设计合成了可先后用于连续检测 $\mathrm{Cu}^{2+}$ 和 $\mathrm{S}^{2-}$ 的 “on-off-on” 型传感器 36 (Scheme 12). 在传感器 36 的 水溶液中, 加入 $\mathrm{Cu}^{2+}$ 后, $\mathbf{3 6}$ 与 $\mathrm{Cu}^{2+}$ 发生 $1: 1$ 的络合, $\mathbf{3 6}$ 的 ESIPT 过程中断，使原来在 373 和 $495 \mathrm{~nm}$ 处的荧光 同时猝灭. 在 36- $\mathrm{Cu}^{2+}$ 的溶液中加入 $\mathrm{S}^{2-}$ 后, $\mathrm{Cu}^{2+}$ 能够与 其结合成 $\mathrm{CuS}$ 沉淀物而离开 36,36 的苂光恢复, 而其他 阴离子则无影响.

其他带有 $-\mathrm{NH}_{2}$ 基团的苯并咪唑化合物，如 2-氨甲 基苯并咪唑，也可广泛应用于荧光探针的设计. 例如, 印度学者 Mathur 等 ${ }^{[39]}$ 从 2,2'-联苯甲酸和 2-氨甲基苯并 咪唑的盐酸盐 $\mathbf{3 7}$ 出发, 先合成联苯类中间体 $\mathbf{3 8}$, 再与碘 乙烷反应得到荧光探针 39 (Scheme 13). 在 39 的甲醇溶 液中, 其与 $\mathrm{Cu}^{2+}$ 发生络合后, 原在 $300 \mathrm{~nm}$ 处的发射峰 减弱，而在 $375 \mathrm{~nm}$ 处产生新的发射峰，而其他金属离子 则无影响，因此 39 对 $\mathrm{Cu}^{2+}$ 有很好的选择性. 在 $\mathrm{Na}_{2}$ EDTA 的存在下, 苂光探针 39 对 $\mathrm{Cu}^{2+}$ 表现为“ off-onoff” 型的化学传感器.

如果将荧光探针 39 中苯并咪唑部分上的乙基更换 为对甲基芳基，则可设计合成另一种菼光探针 40 (Eq 8). 他们在性能上的差异是, 荧光探针 40 在 $300 \mathrm{~nm}$ 处的 荧光发射峰能够被 $\mathrm{Cu}^{2+}$ 和 $\mathrm{Ag}^{+}$猝灭, 但在 $375 \mathrm{~nm}$ 处没 有产生新的苂光发射峰，只对于 $\mathrm{Fe}^{3+}$ 而言存在旧峰猝灭 且有新峰产生的现象，从而能够实现对 $\mathrm{Fe}^{3+}$ 的选择性检 测 ${ }^{[40]}$.

Ghosh 等 ${ }^{[4]}$ 则利用 2 -氨甲基苯并咪唑与葸衍生物 41 反应，设计合成了用于检测 $\mathrm{Cu}^{2+}$ 的三脚架型化学传 感器 42 (Eq. 9), 它是一种检测 $\mathrm{Cu}^{2+}$ 的 “turn-on” 型的化 学传感器.

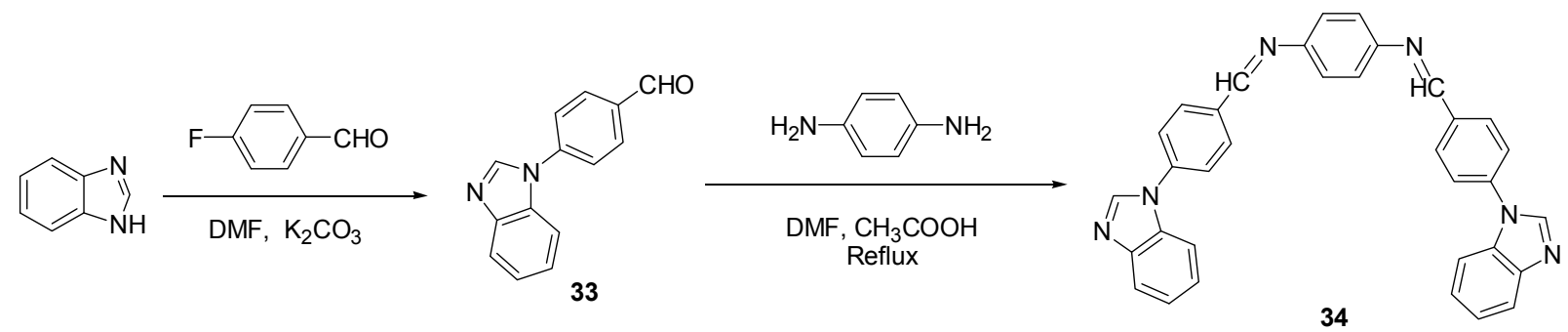

图式 11 传感器 34 的合成

Scheme 11 Synthesis of sensor 34<smiles>Nc1ccccc1-c1nc2ccccc2[nH]1</smiles>

19

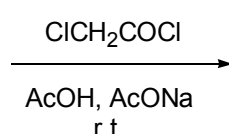

r.t.
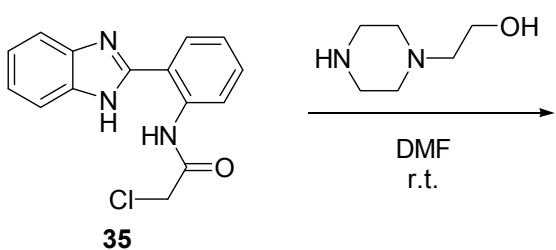

35

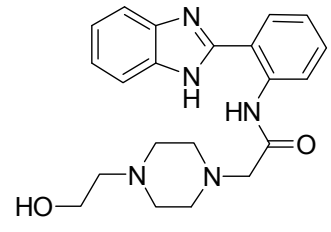

36

图式 12 传感器 36 的合成

Scheme 12 Synthesis of sensor 36 


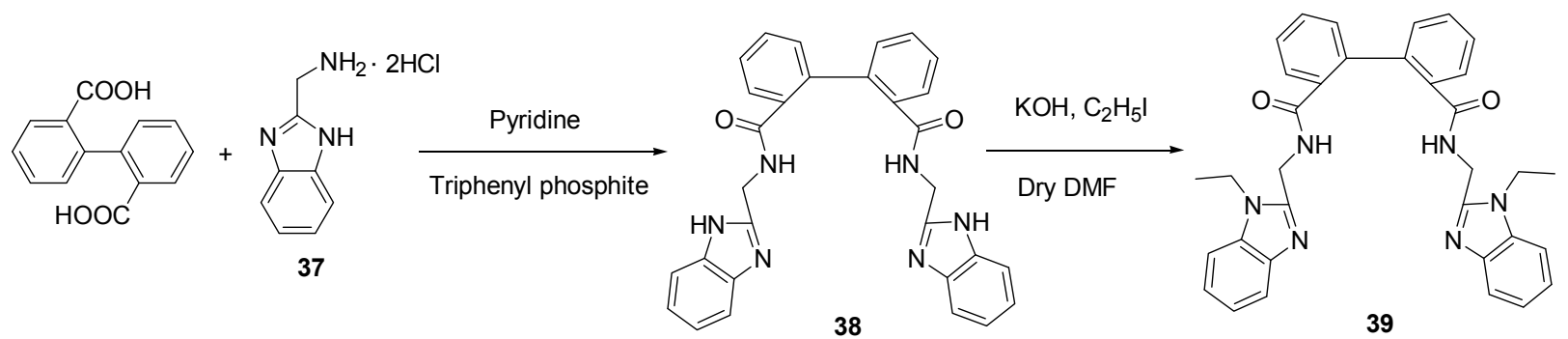

图式 13 苂光探针 39 的合成

Scheme 13 Synthesis of fluorescent probe $\mathbf{3 9}$
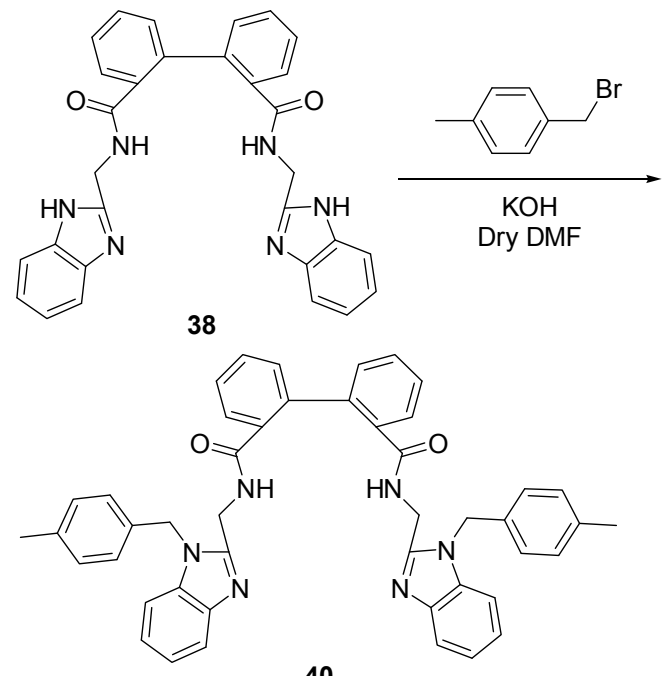

40
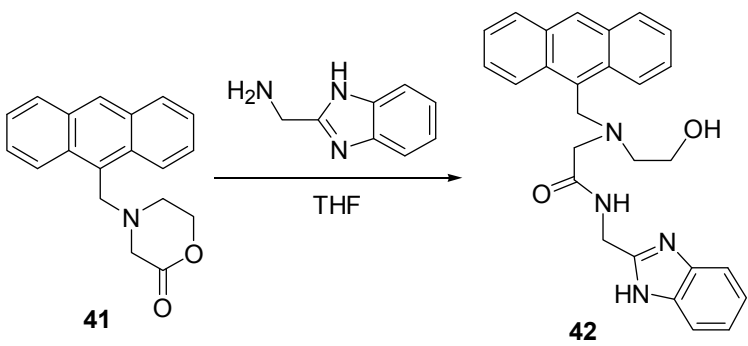

2-氨基苯并咪唑 43 也是一种带有 $\mathrm{NH}_{2}$ 基团的苯并 咪唑化合物, 其应用于 $\mathrm{Cu}^{2+}$ 检测化学传感器的设计也有 报道. 例如, 汤立军课题组 ${ }^{[42]}$ 将其与罗丹明 $\mathrm{B}$ 反应, 所 得化学传感器 44 (Eq. 10)的 $\mathrm{H}_{2} \mathrm{O} / \mathrm{CH}_{3} \mathrm{CN}$ 溶液无色, 但加 入 $\mathrm{Cu}^{2+}$ 后变为粉红色. 这是由于化学传感器 44 能与 $\mathrm{Cu}^{2+}$ 形成 $1: 1$ 的配合物, 络合常数为 $4.27 \times 10^{5} \mathrm{~L} / \mathrm{mol}$, 对 $\mathrm{Cu}^{2+}$ 检测下限达 $2.87 \times 10^{-7} \mathrm{~mol} / \mathrm{L}$.

当 2-(2'-氨基苯基)-苯并咪唑(19)的苯环上的氨基被 同样能参与配位的羟基替换时, 苯并咪唑分子 45 本身 也是检测金属离子的荧光探针, 其易于由邻苯二胺与邻 羟基苯甲酸进行缩合反应而获得(Eq. 11) ${ }^{[43]}$.

同样利用苯并咪唑中 $\mathrm{N}$ 与其他部位 $\mathrm{O}$ 与金属离子 配位的检测原理, 可设计出含有苯并咪唑结构的冠醚类 化合物. 例如, 最近 Karnik 等 ${ }^{[4]}$ 将苯并咪唑化合物 46
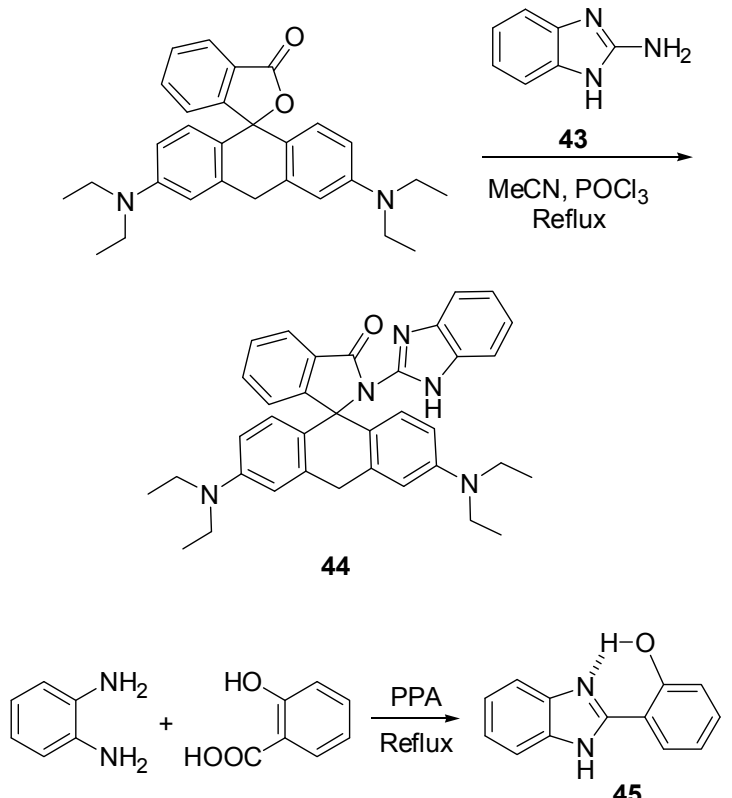

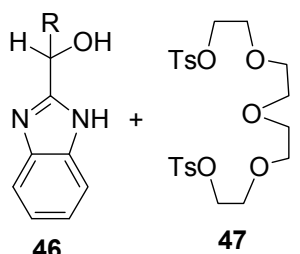

47

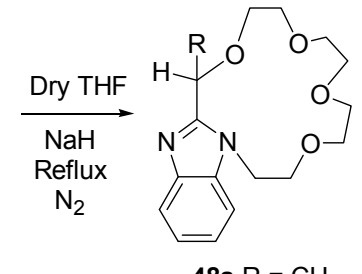

48b $\mathrm{R}=\mathrm{Ph}$

杯芳烃中多羟基的配位作用，也可应用于检测 $\mathrm{Cu}^{2+}$ 的苯并咪唑型化学传感器的设计中。例如，印度学者 Rao 等 ${ }^{[45]}$ 从 2-氯甲基苯并咪唑(49)出发, 通过 Click 反应 将杯 [4]芳烃与苯并咪唑基连接起来, 得到了比率型化 学传感器 50 (Scheme 14). 在其甲醇溶液中，当 $\mathrm{Cu}^{2+}$ 浓 度低时, 传感器 $\mathbf{5 0}$ 中的苯并咪唑和三唑环上的 $\mathrm{N}$ 原子 


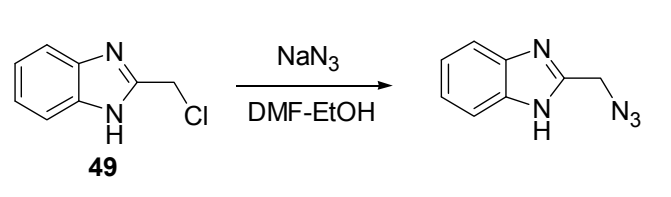

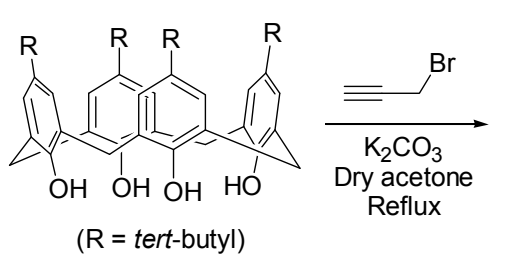

( $R=$ tert-butyl)

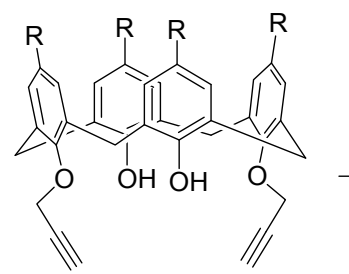

图式 14 传感器 50 的合成

Scheme 14 Synthesis of sensor 50
与 $\mathrm{Cu}^{2+}$ 发生 $1: 1$ 的络合. 随着 $\mathrm{Cu}^{2+}$ 浓度的增加, 不但 苯并咪唑和三唑环上的 $\mathrm{N}$ 原子与 $\mathrm{Cu}^{2+}$ 发生络合, 传感器 50 中杯环上羟基的 $\mathrm{O}$ 原子和三唑环的 $\mathrm{N}$ 原子也与 $\mathrm{Cu}^{2+}$ 发生络合, 最终络合常数为 $7.24 \times 10^{9} \mathrm{~L}^{2} \cdot \mathrm{mol}^{-2}$.

2014 年, Goswami 等 ${ }^{[46]}$ 将 2-氯甲基苯并咪唑类化合 物 51 引进到罗丹明 B 酰肼 11 中, 从而设计合成含有罗 丹明和苯并咪唑的双荧光团的 $\mathrm{Cu}^{2+}$ 荧光探针 $52(\mathrm{Eq}$. 13). 在 $\mathbf{5 2}$ 的 $\mathrm{CH}_{3} \mathrm{CN}$ 溶液中, 加入 $\mathrm{Cu}^{2+}$ 后, $\mathbf{5 2}$ 在 $315 \mathrm{~nm}$ 处的紫外吸收减弱, 在 $556 \mathrm{~nm}$ 处的紫外吸收增强; 而荧 光在原来 $490 \mathrm{~nm}$ 处的发射峰猝灭, 并在 $553 \mathrm{~nm}$ 处产生 一个新的苂光发射峰. 这是由于加入的 $\mathrm{Cu}^{2+}$ 与 $\mathbf{5 2}$ 发生 $1: 1$ 的络合, 导致 52 中的罗丹明 B 结构开环, 而苯并 咪唑单元的发射光谱与开环式罗丹明 B 的吸收光谱能 有效地重叠, 这意味 52 是通过荧光共振能量转移机制 (FRET) 来实现 $\mathrm{Cu}^{2+}$ 的选择性检测的. 不仅如此, 而且能 在 $\mathrm{HeLa}$ 细胞内检测 $\mathrm{Cu}^{2+}$.

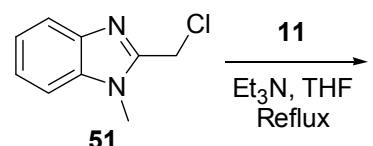

51

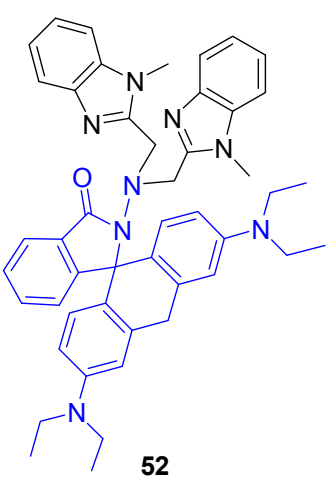

52

\section{4 应用于锌离子的检测}

将苯并咪唑荧光团通过连接体与具有给电子能力 的识别基团连接, 设计合成基于光诱导电子转移(PET) 机理的荧光探针 ${ }^{[47]}$, 用于 $\mathrm{Zn}^{2+}$ 等金属离子检测 ${ }^{[48]}$, 也较 为引人注目. 例如, Chuburu 等 ${ }^{[9-51]}$ 以氮杂大环作为识 别基团, 通过亚甲基与苯并咪唑荧光团相连, 设计合成
了一系列用于检测 $\mathrm{Zn}^{2+}$ 的 “turn-on” 型苂光探针 $\mathbf{5 3} \sim \mathbf{5 5}$ (图 2). 其中, 荧光探针 $\mathbf{5 5}$ 以 1,4,8,11-四氮杂环十四烷为 识别基团, 在甲醇溶液中 55 与 $\mathrm{Zn}^{2+}$ 发生 $1: 1$ 络合, 导 致 PET 过程受阻, 在 $304 \mathrm{~nm}$ 处的苂光明显增强, 苂光量 子产率从 0.02 增加到 0.2 , 检测下限可达 $3.31 \times 10^{-9}$ $\mathrm{mol} / \mathrm{L}^{[51]}$.

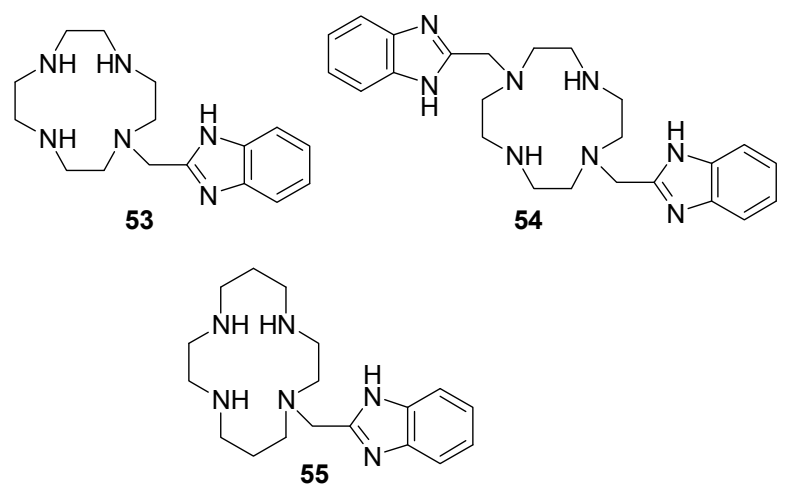

图 2 传感器 $\mathbf{5 3} \sim \mathbf{5 5}$ 的结构式

Figure 2 Structures of chemosensors $53 \sim 55$

除了环状胺类化合物外, 同样具有孤对电子的链状 化合物二乙醇胺也可作为识别基团引进到苯并咪唑苂 光团分子中, 从而设计合成基于 PET机理的 $\mathrm{Zn}^{2+}$ 苂光探 针. 例如, 汤立军课题组 ${ }^{[52]}$ 将具有亲水性的二乙醇胺基 团引入 2-(2'-氨基苯基)-苯并咪唑(19)的衍生物 35 中, 设 计合成了用于检测 $\mathrm{Zn}^{2+}$ 的化学传感器 56 (Eq. 14). 在水 溶液中, 随着 $\mathrm{Zn}^{2+}$ 的加入, 56 与 $\mathrm{Zn}^{2+}$ 发生 $1: 1$ 的络合, 使二乙醇胺上的氮原子到 2-苯基苯并咪唑的 PET 过程 终止, 且络合后 $\mathrm{L}$ 与 $\mathrm{Zn}^{2+}$ 之间发生 ICT, 导致 56 原来在 $367 \mathrm{~nm}$ 处弱的苂光发射峰猝灭, 而在 $427 \mathrm{~nm}$ 处产生新 的荧光发射峰且增强, 对 $\mathrm{Zn}^{2+}$ 的检测下限达 $3.31 \times 10^{-7}$ $\mathrm{mol} / \mathrm{L}$.

如果以化合物 35 与含吡啶基团的胺类化合物反应 (如化合物 57、58), 则可得到基于 ESIPT 机理的 $\mathrm{Zn}^{2+}$ 化 


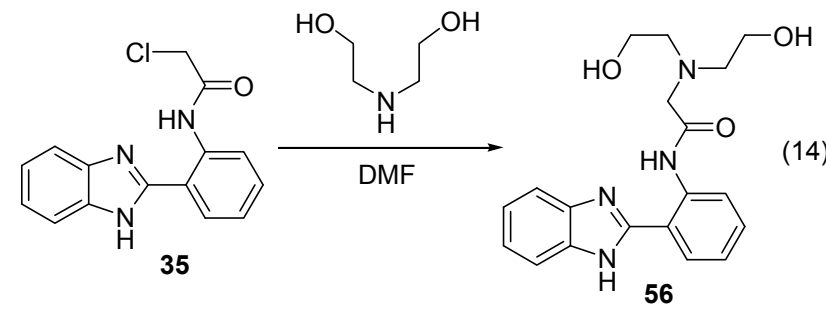

学传感器 59、60 (Scheme 15). 在它们各自的溶液中, 加 入的 $\mathrm{Zn}^{2+}$ 能与它们发生 $1: 1$ 络合, 导致 ESIPT 过程受 阻, 使它们的荧光发生蓝移. 随后, 加有 $\mathrm{Zn}^{2+}$ 的混合溶 液中再加入 $\mathrm{S}^{2-}$, 它们的荧光都能够恢复为原来的状态. 因此, 它们都能够实现 $\mathrm{Zn}^{2+}$ 和 $\mathrm{S}^{2-}$ 的连续检测 ${ }^{[33,54]}$.

利用磺酰胺上 $\mathrm{N}$ 原子与金属离子的配位, 将磺酰胺 引进到苯并咪唑苂光团上, 也能设计出基于 ESIPT 原理 的 $\mathrm{Zn}^{2+}$ 化学传感器. 例如, Cohen 等 ${ }^{[55}$ 利用 2-(2'-氨基苯 基)-苯并咪唑(19)与对甲基苯磺酰氯反应，可得到用于 检测 $\mathrm{Zn}^{2+}$ 的化学传感器 61 (Eq. 15).

当然, 在合成策略上, 也可先引入磺酰胺基再构建 苯并咪唑环, 也可以得到一系列用于检测 $\mathrm{Zn}^{2+}$ 的化学传 感器 $\mathbf{6 2} \sim 64$ (Scheme 16) ${ }^{[56]}$.<smiles>Cc1ccc(S(=O)(=O)Nc2ccccc2-c2nc3ccccc3[nH]2)cc1</smiles>

利用羟基能够参与氢键的形成，将 2-(2'-氨基苯 基)-苯并咪唑(19)中 $2^{\prime}$-位上的氨基替换为羟基, 也可设 计出基于 ESIPT 机理而检测 $\mathrm{Zn}^{2+}$ 的苯并咪唑类化学传 感器. 例如, Fahrni 等 ${ }^{\left[{ }^{[7]}\right.}$ 利用水杨醛类化合物 65 与邻苯 二胺反应，设计合成了苂光探针 66a 和 66b (Eq. 16).
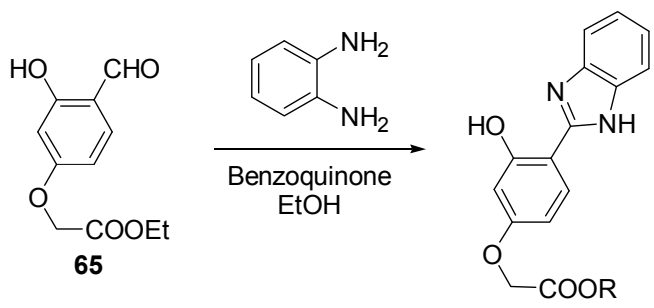

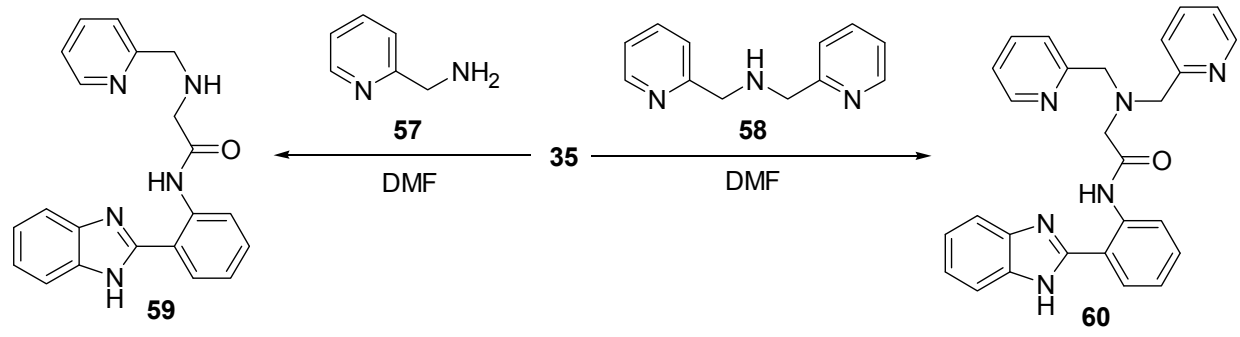

图式 15 传感器 59 和 60 的合成

Scheme 15 Synthesis of sensors 59 and 60

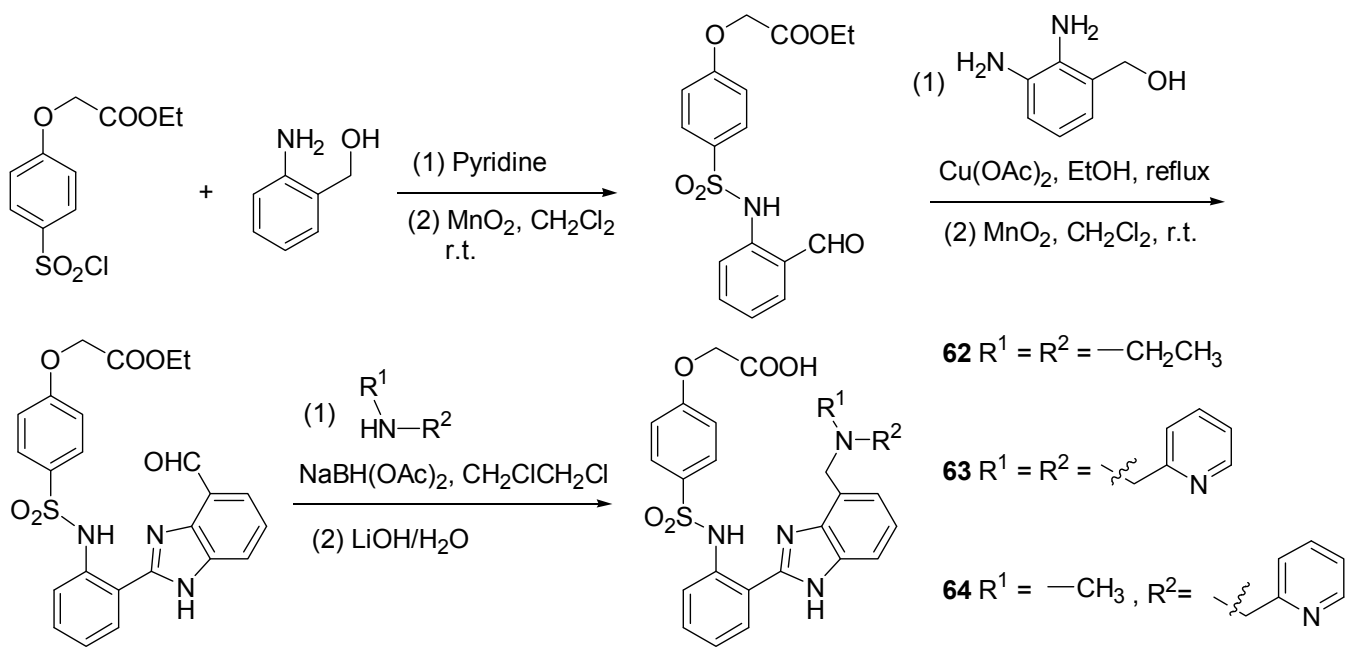

图式 16 传感器 $62 \sim 64$ 的合成

Scheme 16 Synthesis of sensors $62 \sim 64$ 
假如直接利用 2-(2'-着基苯基)-苯并咪唑类化合物 (67)为原料, 也可有效构建基于 ESIPT 机理而检测 $\mathrm{Zn}^{2+}$ 的苯并咪唑类荧光探针 (Eq. 17), 甚至该含有 2 个 2-( $2^{\prime}-$ 羟基苯基)-苯并咪唑结构的苂光探针 68 可在酵母菌细 胞等生物系统中识别 $\mathrm{Zn}^{2+[58]}$.

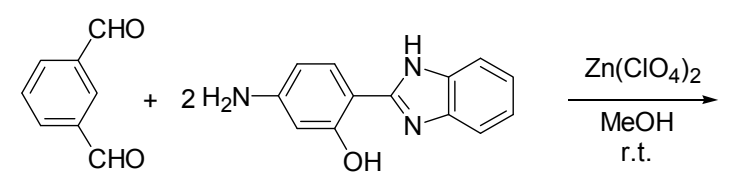

67<smiles>Oc1ccc(/N=C/c2cccc(/C=N/c3ccc(-c4nc5ccccc5[nH]4)c(-c4nc5ccccc5[nH]4)c3)c2)cc1O</smiles>

羰基上的 $\mathrm{O}$ 原子也能够参与金属的配位，利用羰基 中 $\mathrm{O}$ 、苯并咪唑中 $\mathrm{N}$ 与 $\mathrm{Zn}^{2+}$ 配位来设计金属离子探针 也有相关文献报道. 例如, Mashraqui 等 ${ }^{[59]}$ 曾经利用羟醛 缩合反应将苯并咪唑苂光团与查尔酮相连, 设计合成了 基于 ICT 机理的 $\mathrm{Zn}^{2+}$ 的苂光探针 69 (Eq. 18).

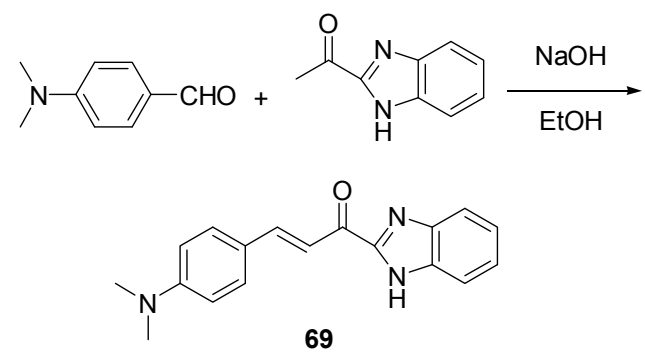

2013 年, Das 等 ${ }^{[60]}$ 利用 2-(2-吡啶基)-苯并咪唑与 2氯乙基苯基硫醚在 DMF 下反应, 设计合成了用于检测 $\mathrm{Zn}^{2+}$ 的荧光探针 70 (Eq. 19). 不仅如此, 利用更多配体 中的 $\mathrm{N} 、 \mathrm{O}$ 参与的配位作用来检测 $\mathrm{Zn}^{2+}$, 也有类似的报 道 ${ }^{[61]}$.

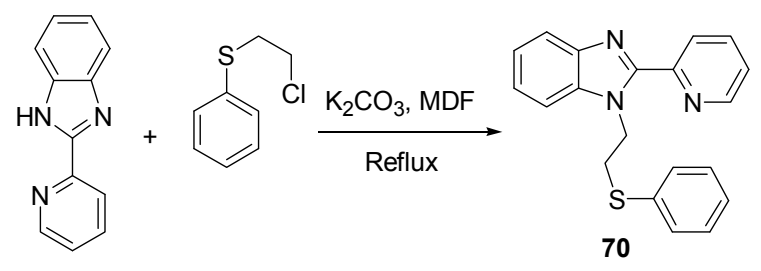

最近, 汤立军课题组 ${ }^{[62]}$ 还以喹啉衍生物 71 与邻苯 二胺缩合, 制备了化合物 72 (Eq. 20). 在 72 的 $\mathrm{CH}_{3} \mathrm{CN} /$ $\mathrm{H}_{2} \mathrm{O}$ 溶液中, 由于 PET 过程的发生, 72 的荧光很弱. 加 入 $\mathrm{Zn}^{2+}$ 后, $\mathrm{Zn}^{2+}$ 与 $\mathbf{7 2}$ 的苯并咪唑 $\mathrm{N}$ 原子和喹啉环上羟基
$\mathrm{O}$ 原子络合, 导致 PET 过程终止, 72 的紫外吸收和苂光 增强, 溶液颜色由微黄色变为绿色, 而其他金属离子则 无影响, 故 72 可实现 $\mathrm{Zn}^{2+}$ 的选择性检测.<smiles>O=Cc1cc2ccccc2nc1O</smiles><smiles>[R2]Oc1nc2ccccc2cc1-c1nc2ccccc2[nH]1</smiles>

目前 $\mathrm{Zn}^{2+}$ 的检测很少应用于生物体内检测, 但国内 学者 Zheng 等 ${ }^{[63]}$ 在这方面取得了重要的突破, 他们报道 了基于苯并咪唑苂光的能用于体内外检测的苂光探针 73, 其易于由水杨醛与 2-氨基苯并咪唑(43)进行缩合而 得到(Eq. 21). 由于发生 ESIPT 过程, 72 的荧光很弱, 但 在不同的溶液中可实现不同金属离子的选择性检测. 例 如, 在 $\mathrm{DMF}$ 溶液中, 加入 $\mathrm{Zn}^{2+}$ 使 73 在 $515 \mathrm{~nm}$ 处的苂 光增强 17 倍; 在 $\mathrm{DMSO}$ 溶液中, 加入 $\mathrm{Al}^{3+}$ 可使 73 在 510 $\mathrm{nm}$ 处的荧光增强 62 倍; 而在甲醇溶液中, 加入 $\mathrm{Zn}^{2+}$ 可 使在 $525 \mathrm{~nm}$ 处的荧光增强 47 倍, 加入 $\mathrm{Al}^{3+}$ 可使在 485 $\mathrm{nm}$ 处的荧光增强 181 倍. 不仅如此, 探针 73 对 HeLa 细胞的毒性低、亲和性高, 故可在 HeLa 细胞内检测 $\mathrm{Zn}^{2+}$ 和 $\mathrm{Al}^{3+}$.

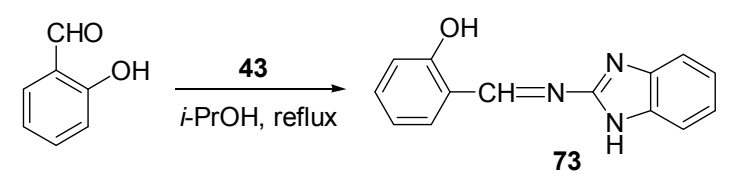

\section{5 应用于铝离子的检测}

利用 2-(2'-氨基苯基)-苯并咪唑(19)同芳香醛缩合而 制备 $\mathrm{Al}^{3+}$ 苂光探针, 近来有较多报道. 例如, Chellappa 等 ${ }^{[64]}$ 利用 2-咪唑甲醛同 19 缩合, 设计了比率型的 $\mathrm{Al}^{3+}$ 苂光探针 74 (Scheme 17). 在 74 的 $\mathrm{DMSO} / \mathrm{H}_{2} \mathrm{O}$ 中, 加入 $\mathrm{Al}^{3+}$ 后, 74 转变为席夫碱形式的开环结构 75, 其与 $\mathrm{Al}^{3+}$ 发生 $1: 1$ 络合, 使紫外吸收光谱中原来 $354 \mathrm{~nm}$ 处的吸 收减弱、在 $409 \mathrm{~nm}$ 处出现新的吸收峰, 而荧光光谱中原 来 $415 \mathrm{~nm}$ 处的发射峰减弱, 在 $472 \mathrm{~nm}$ 处出现新的苂光 发射峰, 并在紫外灯下可看到溶液的颜色由蓝色变为蓝 绿色. 加入 EDTA 后, 其荧光恢复, 这可能是由于 $\mathrm{Al}^{3+}$ 从其配合物中解离出来.

类似地, 利用含有偶氮苯结构的芳香醛, 也可与化 合物 19 反应而合成出苯并咪唑基的荧光探针 76 (Scheme 18). 在 DMSO 溶液中, 加入 $\mathrm{F}^{-}$后, $\mathrm{F}^{-}$能与 $\mathbf{7 6}$ 的羟基形成氢键，影响其 ICT 过程，导致 76 的苂光增强, 溶液颜色在日光灯下由粉红色变为蓝色. 在溶液中, 76 可通过 $1,5-\sigma$ 键迁移, 转变为开环结构 $77, \mathrm{Al}^{3+}$ 的加入也 

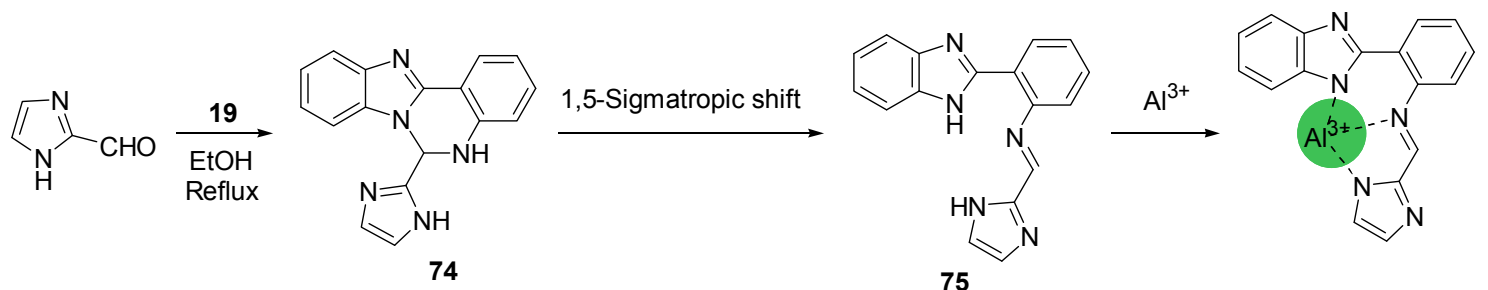

图式 17 苂光探针 74 的合成与作用机理

Scheme 17 Synthesis of fluorescent probe $\mathbf{7 4}$ and its interaction mechanism

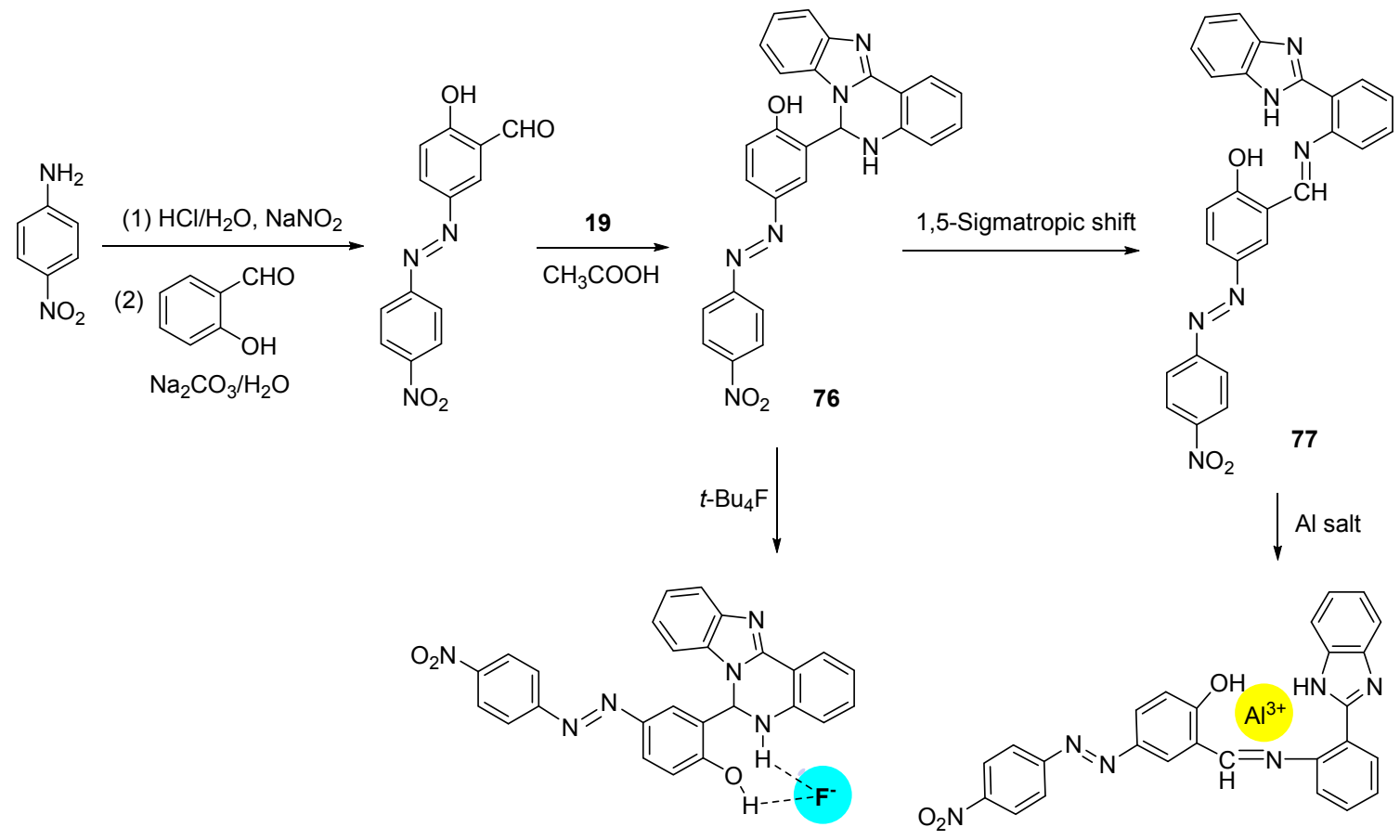

图式 18 苂光探针 76 的合成与作用机理

Scheme 18 Synthesis of fluorescent probe 76 and its interaction mechanism

可使其苂光增强, 溶液颜色变为黄色. 因此, 该成功的 设计可得到分别用于检测 $\mathrm{F}^{-}$和 $\mathrm{Al}^{3+}$ 的 “turn-on” 型苂光 探针 $^{[65]}$.

在国内, 张尊听等 ${ }^{[66]}$ 设计合成嘧啶并 $[1,6-a]$ 苯并咪 唑磺化物荧光探针 78(图 3), 其可在水溶液实现 $\mathrm{Al}^{3+}$ 可 视化性检测.

\section{6 应用于其他金属离子的检测}

除了上述的 $\mathrm{Fe}^{3+} 、 \mathrm{Al}^{3+}$ 外, 其他三价金属离子(如 $\mathrm{Cr}^{3+}$ )的检测也越来越受到关注. 例如, Garcia 等 ${ }^{[67]}$ 合成 了含有 $\mathrm{N} 、 \mathrm{~S}$ 的大环型苯并咪唑类荧光探针 79(图 3), 其 可选择性检测 $\mathrm{Cr}^{3+}$.

利用 2-(2'-氨基苯基)-苯并咪唑(19)与一些特别结构 的芳香醛缩合, 也可构建系列苯并咪唑基检测 $\mathrm{Cr}^{3+}$ 传感 器. 例如, 其与 5-硝基-2-差基苯甲醛反应, 可得化合物 80 (Eq. 22). 在 $\mathrm{CH}_{3} \mathrm{CN} / \mathrm{H}_{2} \mathrm{O}$ 溶液中, $\mathrm{Cr}^{3+}$ 的加入能使 80 在原 $415 \mathrm{~nm}$ 处的苂光猝灭, 并在 $475 \mathrm{~nm}$ 处产生一个新
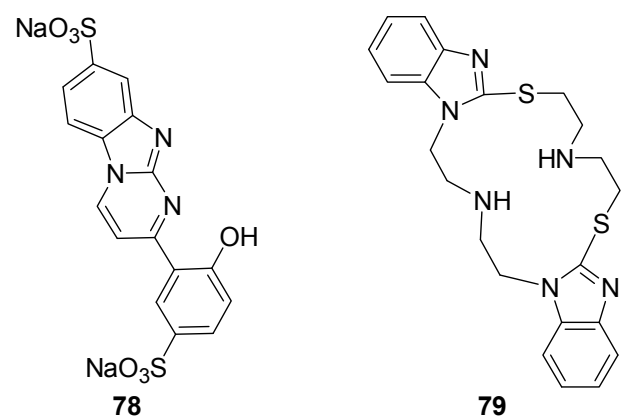

图 3 传感器 78 和 79 的结构式

Figure 3 Structures of chemosensors $\mathbf{7 8}$ and 79
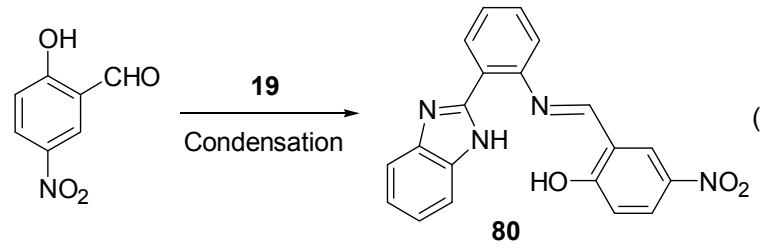
的苂光发射峰; 而加入 $\mathrm{Mg}^{2+}$ 时, 虽然 80 的苂光光谱无 变化, 但 80 在原 $400 \mathrm{~nm}$ 处的紫外吸收峰减弱, 在 350 $\mathrm{nm}$ 处增强, 并在 $385 \mathrm{~nm}$ 处存在等消光点. 因此, 传感 器 80 可通过荧光光谱和紫外光谱的变化, 来分别实现 $\mathrm{Cr}^{3+}$ 和 $\mathrm{Mg}^{2+}$ 的选择性检测. 不仅如此, 80 还可在酵母菌 细胞中实现 $\mathrm{Cr}^{3+}$ 的检测 ${ }^{[68]}$.

类似地, 利用 2-吡啶甲醛与 19 的反应，也可设计检 测 $\mathrm{Cr}^{3+}$ 的传感器 81 (Eq. 23). 在 $\mathrm{CH}_{3} \mathrm{CN} / \mathrm{H}_{2} \mathrm{O}$ 溶液中, 加 入 $\mathrm{Cr}^{3+}$ 能使 81 在原 $420 \mathrm{~nm}$ 处的苂光猝灭, 并在 $470 \mathrm{~nm}$ 处产生一个新的苂光发射峰, 而其他金属离子则无此现 象, 故 81 能够实现对 $\mathrm{Cr}^{3+}$ 的选择性检测, 检测下限为 $1.25 \mu \mathrm{mol} / \mathrm{L}$. 不仅如此, 在 $\mathbf{8 1}-\mathrm{Cr}^{3+}$ 的复合溶液中, 加入 $\mathrm{F}^{-}$能够使其在 $420 \mathrm{~nm}$ 处的荧光增强; 而加入 $\mathrm{HSO}_{4}{ }^{-}$能 够使其在 $420 \mathrm{~nm}$ 处的荧光减弱, 并在 $475 \mathrm{~nm}$ 处产生一 个新的荧光发射峰. 因此, 该设计可以实现 $\mathrm{Cr}^{3+}$ 和 $\mathrm{F}^{-}$ $\left(\mathrm{HSO}_{4}^{-}\right)$的连续性检测. 进一步的对比实验表明, 以 3吡啶甲醛进行设计合成时, 所得苂光传感器的性能与 81 相似，但 4-吡啶甲酫则不能实现 $\mathrm{Cr}^{3+}$ 的选择性检测 ${ }^{[69]}$.
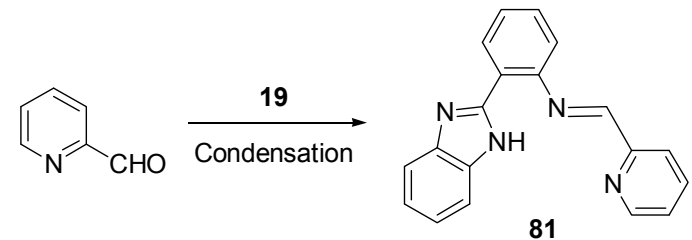

随着银被广泛应用于医药、电子工业、摄影等行业 中, 高浓度银离子对环境的影响越来越严重, 故用传感 器检测环境中的银离子开始受到关注 ${ }^{[70,71]}$. 例如, Rao 等 ${ }^{[72]}$ 以 $\beta$-菜酚为原料, 设计合成了一种苯并咪唑基的 “turn-on” 型探针 82 (Scheme 19). 在 $\mathrm{MeOH} / \mathrm{H}_{2} \mathrm{O}$ 溶液

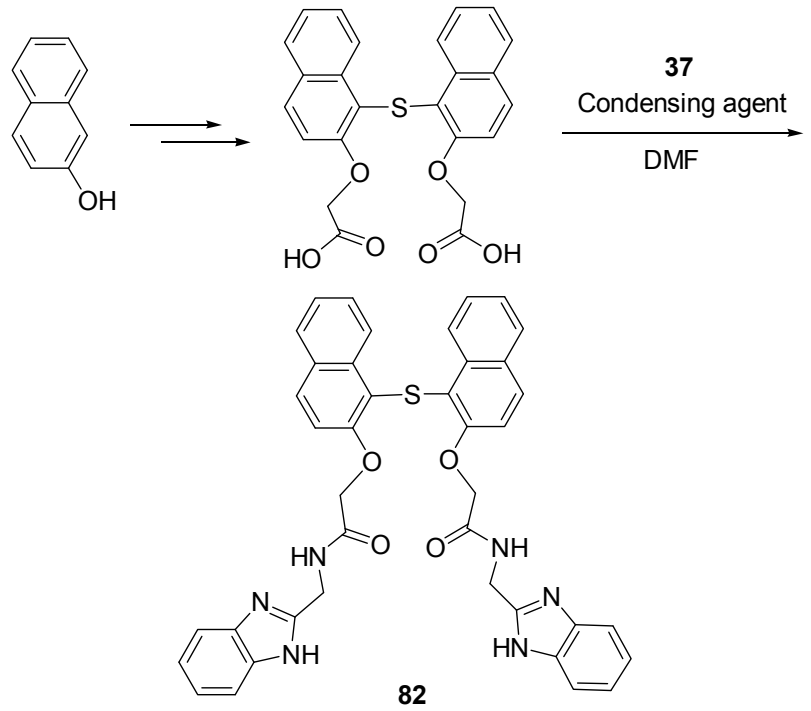

图式 19 苂光探针 82 的合成

Scheme 19 Synthesis of fluorescent probe $\mathbf{8 2}$
中，探针 82 在 $360 \mathrm{~nm}$ 处有一微弱的发射峰，加入不同 的金属离子, 其中 $\mathrm{Ag}^{+}$与 82 发生 $1: 1$ 络合, 导致 82 的 苂光红移至 $390 \mathrm{~nm}$ 并显著增强, 络合常数为 $4.07 \times 10^{4}$ $\mathrm{L} / \mathrm{mol}$, 检测下限达 $430 \mathrm{ppb}$. 利用 $\mathbf{8 2}-\mathrm{Ag}^{+}$进一步分别与 20 多种氨基酸相互作用, 发现半胱氨酸、天门冬氨酸以 及谷氨酸能够使其苂光猝灭.

\section{2 应用于阴离子的检测}

氟是人体必需的微量元素之一, 对骨骼和牙齿的形 成具有重要作用, 但过量的氟会造成氟中毒, 所以在环 境监测及食品安全等领域氟离子的检测受到关注. 由于 具有灵敏度高和选择性好等优点，苂光方法被广泛用于 检测氟离子 ${ }^{[73]}$. 其中, 有很多文献报道了苯并咪唑类化 合物与金属离子络合而构成的荧光化学传感器应用于 氟离子的检测 ${ }^{[74 ~ 76]}$. 例如, Wang 等 ${ }^{[74]}$ 报道了以 2-(2'-吡 啶基)苯并咪唑(1)与金属铕配位而应用于 $\mathrm{F}^{-}$检测的传感 器.

通过多羧基芳香酸与邻苯二胺类化合物的缩合反 应，可构建含有多个苯并咪唑结构的 $\mathrm{F}^{-}$检测传感器. 例 如, Iyer 等 ${ }^{[77]}$ 利用间二苯甲酸与 4,5-二甲基邻苯二胺反 应, 得到了化学传感器 83 (Eq. 24). 在 83 的 $\mathrm{CH}_{3} \mathrm{CN}$ 溶 液中, 加入 $\mathrm{F}^{-}$后, 氢键的形成导致 83 原在 $339 \mathrm{~nm}$ 处的 紫外吸收峰减弱, 且在 $368 \mathrm{~nm}$ 处有一个等消光点; 83 原 来 $393 \mathrm{~nm}$ 处的苂光发射峰猝灭, 并红移至 $403 \mathrm{~nm}$ 处. 由于其他阴离子对 83 紫外和荧光的影响程度都远不及 $\mathrm{F}^{-}$，故 83 能够实现 $\mathrm{F}^{-}$的选择性检测.

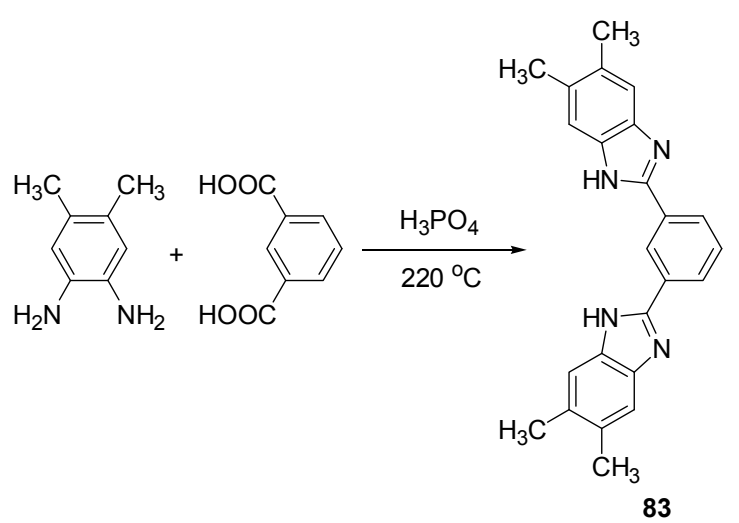

也可利用芳香醛类与邻苯二胺类化合物的缩合反 应来构建含有苯并咪唑基的 $\mathrm{F}^{-}$传感器, 如 Luxami 等 ${ }^{[78]}$ 制备的荧光探针 84 (Eq. 25). 在 $\mathrm{CH}_{3} \mathrm{CN}$ 溶液中, 加入 $\mathrm{F}^{-}$能使 84 在原 $335 \mathrm{~nm}$ 处的紫外吸收减弱, 在 $360 \mathrm{~nm}$ 出 现新的紫外吸收; 原 $540 \mathrm{~nm}$ 处的荧光发射峰减弱, 并在 $420 \mathrm{~nm}$ 处产生新的苂光发射峰. 这是由于加入 $\mathrm{F}^{-}$后, 导 致 84 中的羟基失去质子, 抑制了羟基到苯并咪唑的 $\mathrm{N}$ 原子上的 ESIPT 过程. 因此, 84 可通过紫外吸收光谱和 
荧光光谱的改变, 实现 $\mathrm{F}^{-}$的选择性检测.<smiles>Nc1ccc(C(=O)c2ccccc2)cc1N</smiles><smiles>O=C(c1ccccc1)c1ccc2[nH]c(-c3ccccc3O)nc2c1</smiles>

(25)

类似地，利用含有醛基的氟硼二吡咯类化合物 85 与邻苯二胺反应, 可设计合成用于 $\mathrm{F}^{-}$检测的化学传感 器 86 (Eq. 26). 在 86 的 $\mathrm{CH}_{3} \mathrm{CN}$ 溶液中, 由于苯并咪唑 上的 $\mathrm{NH}$ 与 $\mathrm{F}$ 原子生成分子内氢键, PET 过程受阻, 86 有强的苂光性能, 苂光量子产率大约 0.5. 加入 $\mathrm{F}^{-}$后, 86 中的分子内氢键被破坏，导致 86 的 PET 过程开启而荧 光猝灭, 溶液颜色在日光灯下由苂光性的桃红色变为非 荧光性的蓝色. 继续往溶液加入三氟乙酸(TFA), 86 的 荧光和颜色恢复为原状. 因此, 86 可在选择性检测 $\mathrm{F}^{-}$中 多次重复使用 ${ }^{[79]}$.

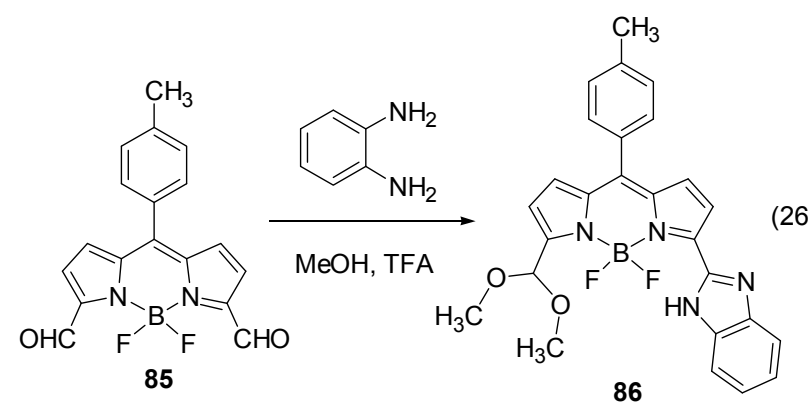

利用醛类化合物对 2-氨基苯并咪唑化合物进行结 构改造, 可得到含有 $\mathrm{C}=\mathrm{N}$ 的苯并咪唑类 $\mathrm{F}^{-}$传感器. 例 如, Tolpygin 等 ${ }^{[80]}$ 将 2-氨基苯并咪唑(43)与含有葱基的 醛类化合物 87 缩合, 设计合成了荧光探针 88 (Eq. 27).

2-氨基苯并咪唑类化合物还可与芳基二酰卤类化合 物发生亲核取代反应, 有效地构建出含有两个苯并咪唑 基的 $\mathrm{F}^{-}$传感器. 例如, Jang 等 ${ }^{[81]}$ 利用间二苯酰胺氯与化
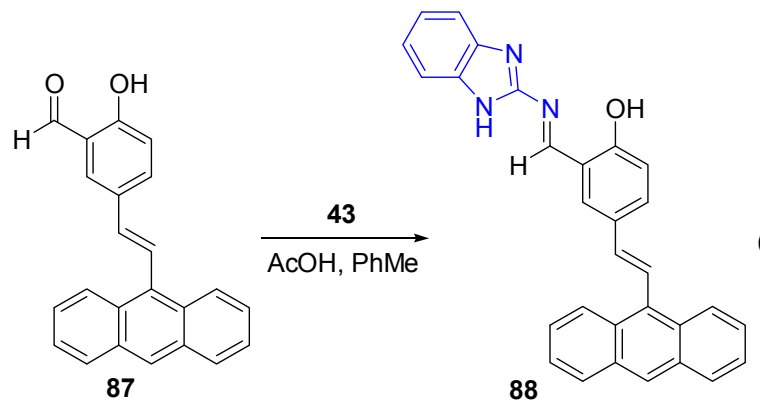

合物 89 反应，得到化学传感器 90 (Eq. 28). 在 90 的 $\mathrm{CH}_{3} \mathrm{CN} / \mathrm{DMSO}$ 溶液中, 加入 $\mathrm{F}^{-}$后, 由于苯并咪唑上激 发态的电子转移到了硝基上，导致 90 在原 277 和 339 $\mathrm{nm}$ 处的紫外吸收减弱, 并在 $429 \mathrm{~nm}$ 处出现一个新的紫 外吸收峰, 溶液颜色可通过肉眼观察到从无色变为黄 色. $\mathrm{AcO}^{-}$也有类似的效果, 因此 90 可成功地用作为 $\mathrm{F}^{-}$ 和 $\mathrm{AcO}^{-}$的比色型化学传感器, 检测下限达 $100 \mu \mathrm{mol} / \mathrm{L}$.
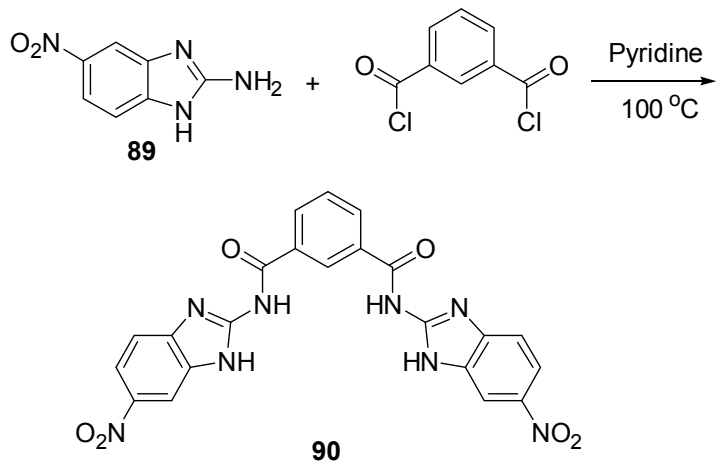

利用类似的思路, Lin 等 ${ }^{[82]}$ 以氨基酸等为原料, 经过 系列反应，设计合成同时含有苯并咪唑和 1,10-邻二氮 杂菲荧光团的苂光探针 91a 91b (Scheme 20). 在 91a 的 DMSO 溶液中, 加入 $\mathrm{F}^{-}$后, 由于苯并咪唑上的 $\mathrm{NH}$ 发 生去质子化, 导致苯并咪唑基可自由旋转, 通过 PET 过 程使 91a 的荧光发生猝灭. 但是, 加入 4 equiv. 的 $\mathrm{Cl}^{-}$后, 加入的 $\mathrm{Cl}^{-}$与 $91 \mathrm{a}$ 上的两个苯并咪唑基的 $\mathrm{NH}$ 以氢键结 合，使 91a 分子的刚性增加，故荧光增强，苂光量子产 率从 0.09 增加到 0.16. 加入 $\mathrm{Br}^{-}$和 $\mathrm{I}^{-}$时, 有与 $\mathrm{Cl}^{-}$相似的

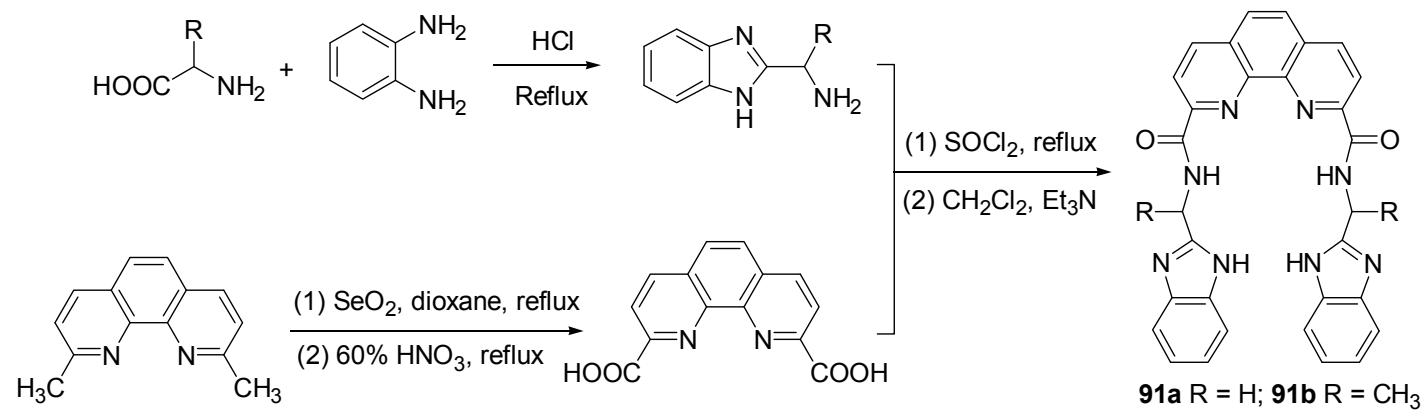

图式 20 苂光探针 91 的合成

Scheme 20 Synthesis of fluorescent probes 91 
影响, 但灵敏性远不及 $\mathrm{Cl}^{-}$. 对探针 $\mathbf{9 1 b}$, 由于 $\mathrm{CH}_{3}$ 的给 电子作用不利于 $\mathrm{Cl}^{-} 、 \mathrm{Br}^{-}$和 $\mathrm{I}^{-}$等卤离子与 $\mathrm{NH}$ 形成氢键, 故增强了对 $\mathrm{F}^{-}$的选择性.

2-(2'-羟基苯基)-苯并咪唑(45)是一个可用于金属离 子检测的传感器 ${ }^{[43]}$, 但也可通过引进叔丁基二甲基硅基 (TBS)来抑制其 ESIPT 过程, 从而设计合成出比率型苂 光传感器 92 检测 $\mathrm{F}^{-}$(Scheme 21). 在 $\mathbf{9 2}$ 的 DMF 溶液中, 加入 $\mathrm{F}^{-}$后 TBS 从 92 中脱离下来, 使 ESIPT 过程开启, 导致原 $360 \mathrm{~nm}$ 处的苂光猝灭, 并在 $425 \mathrm{~nm}$ 处产生一个 新的苂光发射峰. 由于其他阴离子无影响, 故 92 能实现 $\mathrm{F}^{-}$的选择性检测, 检测下限达 $0.19 \mu \mathrm{mol} / \mathrm{L}^{[83]}$.

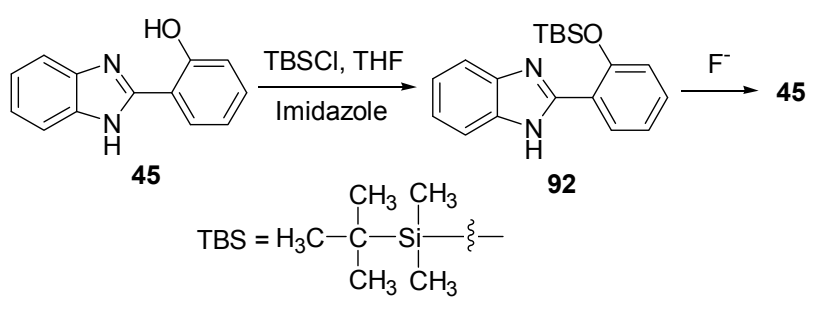

图式 21 苂光探针 92 的合成与作用机理

Scheme 21 Synthesis of fluorescent probe 92 and its interaction mechanism

在 2-(2'-着基苯基)-苯并咪唑(45)上通过引入 $\mathrm{N}=\mathrm{N}$ 来改善苯并咪唑与阴离子的结合能力, 亦可有效地设计 含有苯并咪唑基的阴离子传感器, 如化合物 93 (Scheme 22). 在 $\mathrm{CH}_{3} \mathrm{CN}$ 溶液中, 加入 $\mathrm{F}^{-} 、 \mathrm{AcO}^{-} 、 \mathrm{CN}^{-}$以及 $\mathrm{H}_{2} \mathrm{PO}_{4}{ }^{-}$后, 93 的紫外吸收从 $315 \mathrm{~nm}$ 处红移至 $470 \mathrm{~nm}$ 处, 溶液颜色由无色变为橙色. 通过 ${ }^{1} \mathrm{H}$ NMR 测试表明, 这 些阴离子都能与 93 发生 $2: 1$ 的络合, 络合能力的顺序 为: $\mathrm{AcO}^{-}>\mathrm{CN}^{-}>\mathrm{F}^{-}>\mathrm{H}_{2} \mathrm{PO}_{4}^{-[84]}$.

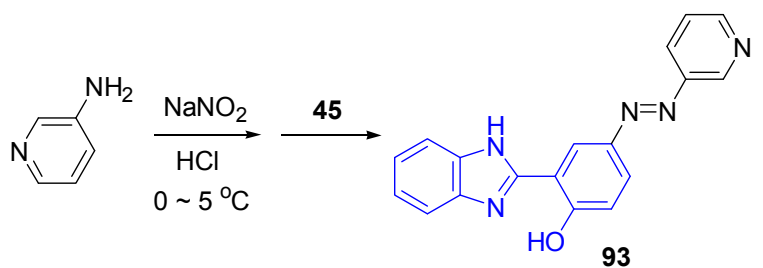

图式 22 化合物 93 的合成

Scheme 22 Synthesis of compound 93

除了 $\mathrm{F}^{-}$外，其他卤素离子(如 $\mathrm{Cl}^{-} 、 \mathrm{I}^{-}$等)的荧光法检 测也备受关注 ${ }^{[82]}$. 由于 $\mathrm{I}^{-} 、 \mathrm{Cl}^{-}$的离子半径比 $\mathrm{F}^{-}$大得多, 故在目前为数不多的文献局限于苯并咪唑类化合物与 金属离子络合而构成苂光化学传感器的情况下 ${ }^{[85,86]}$, 设 计可用于检测 $\mathrm{I}^{-} 、 \mathrm{Cl}^{-}$的传感器更具有挑战性, 这方面 Jang 等 ${ }^{[87]}$ 以化合物 26 与 2 -氨基苯并咪唑(43)反应, 设计 合成了三脚架型的苯并咪唑基传感器 94 (Eq. 29). 在 $\mathrm{CH}_{3} \mathrm{CN} / \mathrm{H}_{2} \mathrm{O}$ 溶液中, 加入的 $\mathrm{I}^{-}$能与 94 的 $\mathrm{NH}_{2}$ 以氢键结 合, 导致 94 的紫外吸收从原 $258 \mathrm{~nm}$ 处蓝移到 $248 \mathrm{~nm}$ 处
并增强，且苂光发生猝灭，而其他阴离子则无影响，故 94 可实现 $\mathrm{I}^{-}$的选择性检测, 检测下限达 $7.46 \times 10^{-6}$ $\mathrm{mol} / \mathrm{L}$.

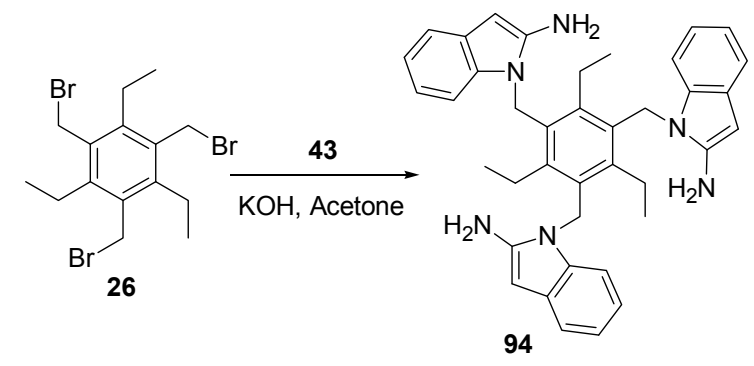

由于 $\mathrm{CN}^{-}$具有很强的毒性, 其识别与检测在环境科 学和生命科学具有重要的意义 ${ }^{[88]}$, 目前也是苯并咪唑基 苂光化学传感器的关注点之一 ${ }^{[89]}$. 例如, $\mathrm{Hu}$ 等 ${ }^{[90]}$ 利用邻 苯二胺与含有羟基的菜醛缩合，设计合成了含有萗基和 苯并咪唑基的比色化学传感器 95 (Eq. 30). 在 $\mathrm{H}_{2} \mathrm{O}$ / $\mathrm{DMSO}$ 溶液中, 加入的 $\mathrm{CN}^{-}$能够使 95 上的羟基脱去质 子, 从而影响了 95 分子 ICT 过程, 使 95 在 $450 \mathrm{~nm}$ 处的 荧光显著增强, 溶液颜色由浅蓝色变成深蓝色, 检测下 限低于 WHO 的标准, 可达 $8.8 \times 10^{-8} \mathrm{~mol} / \mathrm{L}$, 且其他阴 离子对其没有任何干扰.<smiles>O=Cc1c(O)ccc2ccccc12</smiles>
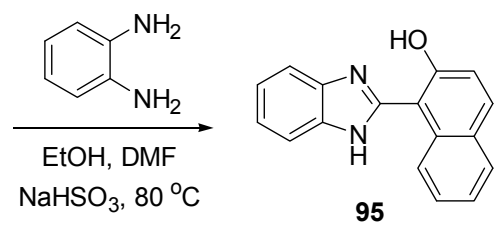

(30)

如果对芳香醛苯环上的羟基进一步引进亲水性基 才, 可设计得到能在水溶液检测 $\mathrm{CN}^{-}$的荧光探针, 如化 合物 96 (Scheme 23). 在水溶液中, 96 能与加入的 $\mathrm{Hg}^{2+}$ 络合形成 96- $\mathrm{Hg}^{2+}$ 配合物而导致其苂光猝灭, 继续加入 $\mathrm{CN}^{-}$后, $\mathrm{Hg}^{2+}$ 离开 96 , 从而其荧光恢复. 其他阴离子则 无此现象, 故 96- $\mathrm{Hg}^{+}$配合物能实现 $\mathrm{CN}^{-}$的选择性检测, 检测下限达 $0.19 \mu \mathrm{mol} / \mathrm{L}$. 值得注意的是, 96 能在 $\mathrm{HeLa}$ 细胞中实现 $\mathrm{CN}^{-}$的检测 ${ }^{[91]}$.

利用邻苯二胺与多羧基类化合物的缩合反应，可用 于构建检测 $\mathrm{AcO}^{-}$的苯并咪坐基荧光探针, 如 Iyer 等 ${ }^{[92]}$ 制备的化合物 97 (Eq. 31). 在 $\mathrm{CH}_{3} \mathrm{CN}$ 溶液中, 加入的 $\mathrm{AcO}^{-}$能与 97 以氢键结合, 使原在 $327 \mathrm{~nm}$ 处的紫外吸收 减弱, 在 $368 \mathrm{~nm}$ 有新的紫外吸收, 在 $350 \mathrm{~nm}$ 处出现等 消光点; 苂光光谱中, 使其原在 $375 \mathrm{~nm}$ 处的荧光猝灭. 97 用于 $\mathrm{AcO}^{-}$的选择性检测, 检测下限可达 $10^{-7} \mathrm{~mol} / \mathrm{L}$.

利用荧光法检测其他的一价阴离子(如 $\mathrm{HSO}_{4}^{-}$、 $\mathrm{HSO}_{3}^{-}$) 也备受关注. 例如, Chattopadhyay 等 ${ }^{[93]}$ 利用苯并 咪唑类化合物 19 与取代苯甲醛反应, 得到了可用于 


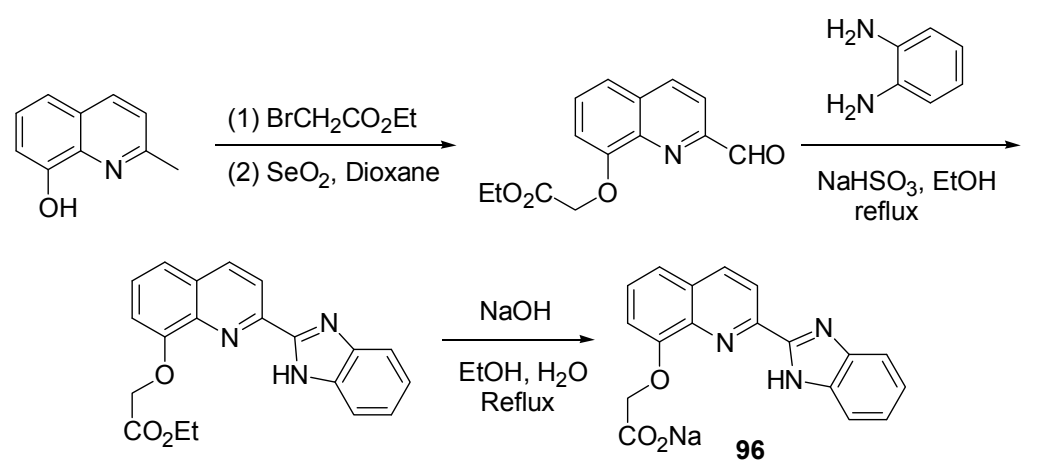

图式 23 化合物 96 的合成

Scheme 23 Synthesis of compound 96

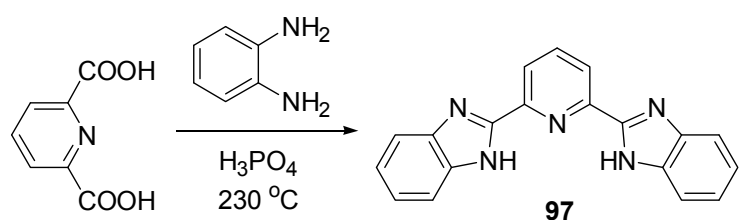

(31)

$\mathrm{HSO}_{4}^{-}$选择性检测的苯并咪唑基传感器 98 (Eq. 32). 由 于对细胞没有毒性, 98 能在 $\mathrm{HeLa}$ 细胞内实现 $\mathrm{HSO}_{4}{ }^{-}$的 检测. 当 98 上 $\mathrm{R}$ 基为硝基时, 传感器 $98 \mathrm{a}$ 在 $\mathrm{CH}_{3} \mathrm{CN}$ 溶 液中能与 $\mathrm{HSO}_{4}^{-}$发生 $1: 1$ 络合, 导致 98a 的 PET 过程 终止，使其在 $485 \mathrm{~nm}$ 处苂光增强; 当 98 上 $\mathrm{R}$ 基为甲氧 基时, 加入 $\mathrm{HSO}_{4}^{-}$后, PET 过程的终止不但使传感器 $\mathbf{9 8 b}$ 在 $485 \mathrm{~nm}$ 处苂光增强, 且在原 $430 \mathrm{~nm}$ 处的苂光减弱. 因此, 仅 98b 能够设计成比率型传感器.<smiles>[R]c1ccc(C=O)cc1</smiles>
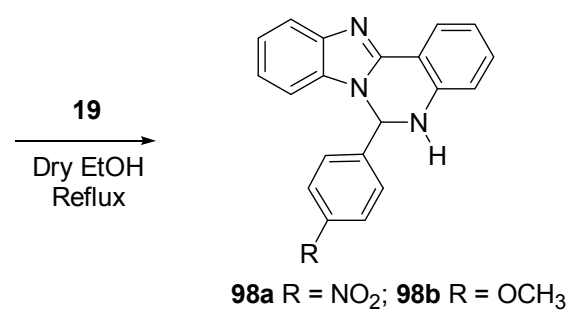

利用对二苯甲醛与等物质的量邻苯二胺反应后剩 余一个酫基的特点, 可设计合成用于检测 $\mathrm{HSO}_{3}^{-}$的苯并 咪唑类传感器 99 (Scheme 24). 在 $\mathrm{CH}_{3} \mathrm{OH} / \mathrm{H}_{2} \mathrm{O}$ 溶液中, 加入的 $\mathrm{HSO}_{3}{ }^{-}$与 99 反应, 使 $\mathbf{1 0 0}$ 的 ICT 过程终止, 导致 99 原在 $320 \mathrm{~nm}$ 处的紫外吸收减弱, 在 $304 \mathrm{~nm}$ 处出现新 的紫外吸收峰; 在原 $368 \mathrm{~nm}$ 处的苂光猝灭, 但原 498 $\mathrm{nm}$ 处的苂光增强. 由于其他阴离子则无此现象, 故 99 能够实现 $\mathrm{HSO}_{3}^{-}$的选择性检测, 检测下限达 0.4 $\mu \mathrm{mol} / \mathrm{L}^{[94]}$.

除了各种一价阴离子, 用于检测二价阴离子(如 $\mathrm{HAsO}_{4}^{2-} 、 \mathrm{~S}^{2-}$ 等)的苯并咪唑基传感器也有相关报道. 例 如, Sahana 等 ${ }^{[95]}$ 报道了以 2-(2'-吡啶基)苯并咪唑(1)与金 属锰配位而应用于 $\mathrm{HAsO}_{4}{ }^{2-}$ 检测的传感器, 其可用于细 胞内检测.

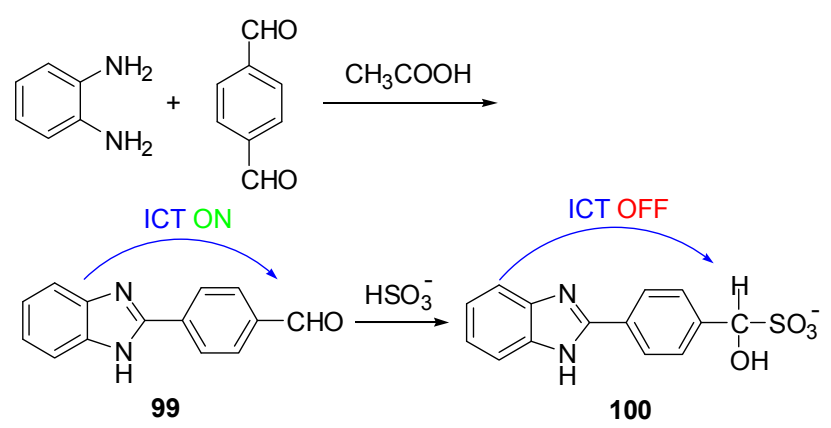

图式 24 传感器 99 的合成与作用机理

Scheme 24 Synthesis of sensor 99 and its interaction mechanism

Das 等 ${ }^{[96]}$ 利用卤代烃 23 与 2-氨基苯并咪唑(43)的反 应，设计合成了三脚架的荧光探针 101 (Eq. 33). 101 具 有高荧光性能, 在 $\mathrm{CH}_{3} \mathrm{CN} / \mathrm{H}_{2} \mathrm{O}$ 溶液中其能够与 $\mathrm{Cu}^{2+}$ 形 成 101- $\mathrm{Cu}^{2+}$ 配合物而导致荧光猝灭. 继续加入 $\mathrm{S}^{2-}, \mathrm{CuS}$ 沉淀的生成可使 101 的苂光恢复. 其他阴离子无此现象, 故该设计可成功实现 $\mathrm{Cu}^{2+} 、 \mathrm{~S}^{2-}$ 连续性检测.
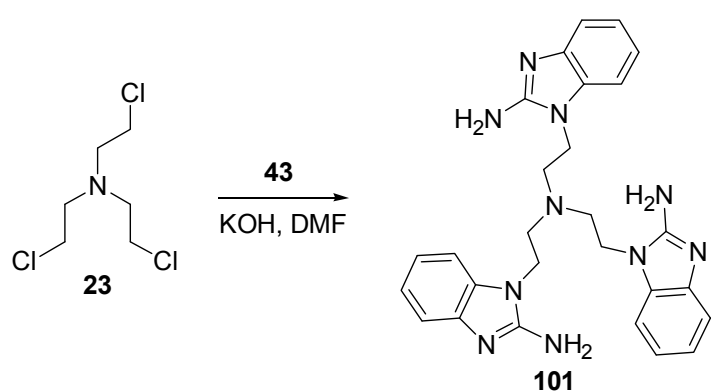

(33)

利用含有一个醛基的邻萗二酚类化合物与邻苯二 胺反应, 可设计同时含有联䒺和苯并咪唑结构的苂光探 针 102 (Eq. 34), 102 能与 $\mathrm{Cu}^{2+}$ 以 2: 1 络合, 形成 102$\mathrm{Cu}^{2+}$ 配合物. 在磷酸盐缓冲溶液-DMF 中, 不同 $\mathrm{pH}$ 对苂 光探针有着不同的影响. 例如, 当 $\mathrm{pH}=7.4$ 时, 加入 $\mathrm{S}^{2-}$ 能够使 102- $\mathrm{Cu}^{2+}$ 配合物在 $590 \mathrm{~nm}$ 处的苂光增强, 溶液 颜色由蓝色变为橙色, 而 $\mathrm{pH}=10$ 时, 加入 $\mathrm{S}^{2-}$ 能够使 
102- $\mathrm{Cu}^{2+}$ 配合物在 $517 \mathrm{~nm}$ 处的苂光增强, 溶液颜色由蓝 色变为绿色. 不仅如此, 102- $\mathrm{Cu}^{2+}$ 配合物除了识别 $\mathrm{S}^{2-}$ 外, 还可识别溶液中的 $\mathrm{HS}^{-}$和空气中的 $\mathrm{H}_{2} \mathrm{~S}$ 等硫源 ${ }^{[97]}$.<smiles>O=Cc1cc2ccccc2c(-c2c(O)ccc3ccccc23)c1O</smiles><smiles>COC(C)(C)C</smiles><smiles>O=[N+]([O-])c1ccc2ccccc2c1-c1c(O)c(-c2nc3ccccc3[nH]2)cc2ccccc12</smiles>

将苯并咪唑基团嵌入聚合物中，也可利用其苂光性 质实现苂光检测 ${ }^{[98]}$, 包括阴离子的检测. 例如, Iyer 等 ${ }^{[99]}$ 利用多溴化合物对 2-苯基苯并咪唑 103 进行 $N$-烷 基化, 之后再通过 Suzuki 偶联反应，设计合成了可用于 检测唾液中的无机磷酸盐的荧光探针 104 (Scheme 25). 104 能够与 $\mathrm{Fe}^{3+}$ 结合, 形成的 $104-\mathrm{Fe}^{3+}$ 配合物会导致 104 的苂光猝灭, 而加入的无机磷酸盐能够使 $\mathrm{Fe}^{3+}$ 从 104$\mathrm{Fe}^{3+}$ 脱离出来, 导致 104 苂光恢复.

B
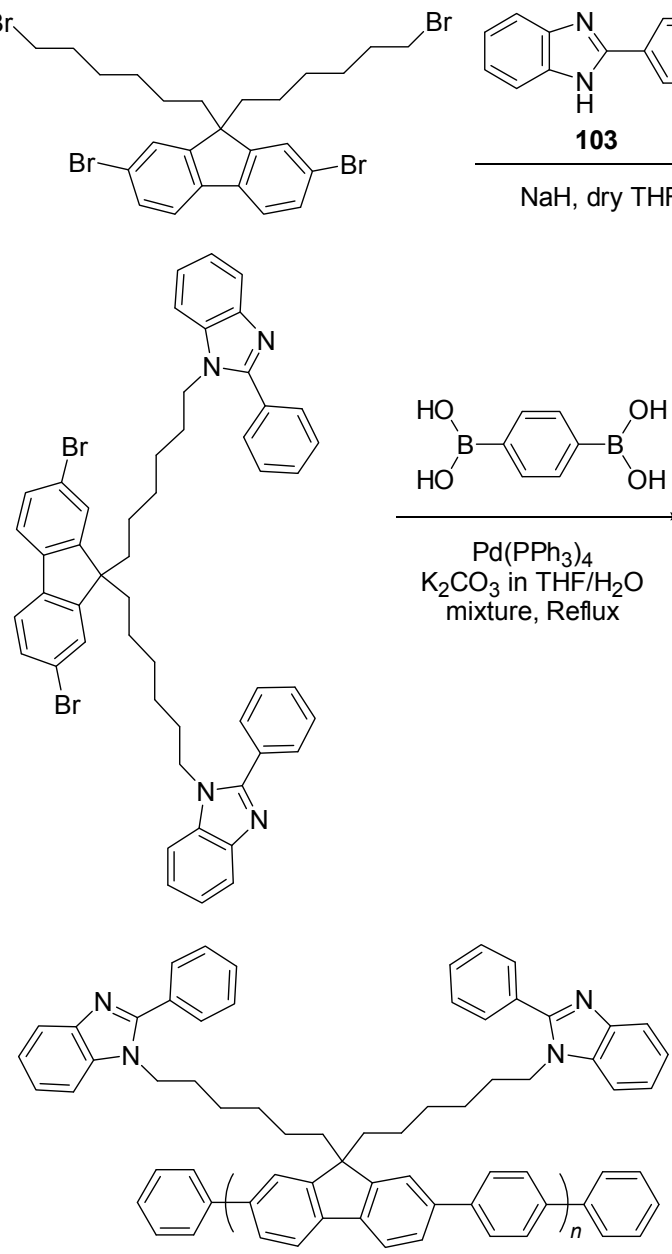

104

图式 25 苂光探针 104 的合成

Scheme 25 Synthesis of fluorescent probe $\mathbf{1 0 4}$
除了以上苯并咪唑类苂光探针可应用于阴离子的 检测外，一些刚性 L 形的苯并咪唑类化合物(如 105、106, 图 4)也可用于检测阴离子(如 $\mathrm{F}^{-} 、 \mathrm{AcO}^{-}$), 甚至这种特别 结构的苯并咪唑类苂光探针还可用于检测酸、碱 ${ }^{[100]}$
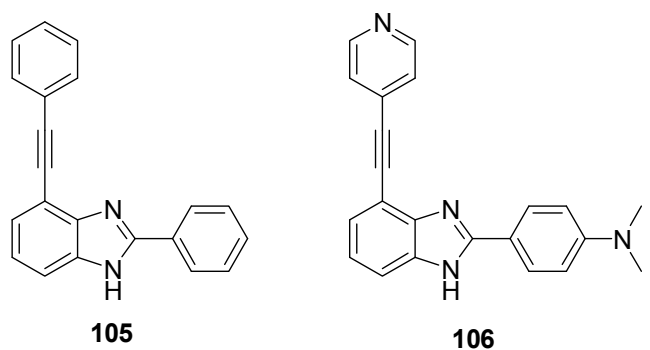

图 4 传感器 105 和 106 的结构式

Figure 4 Structures of chemosensors 105 and 106

\section{3 应用于其他无机物的检测}

除前面提及的 $\mathrm{H}_{2} \mathrm{~S}$ 外 ${ }^{[97]}$ ，随着苂光方法在检测领域 的快速发展，也有苯并咪唑基荧光探针应用于 $\mathrm{NO} 、 \mathrm{CO}_{2}$ 等无机物气体检测的文献报道. 例如，陈江宁等 ${ }^{[101]}$ 报 道, 2-(2'-着基苯基)-苯并咪唑(45)与铜离子可形成配合 物, 其能应用于 $\mathrm{NO}$ 的选择性检测, 甚至 $45-\mathrm{Cu}^{2+}$ 配合物 亦可应用于小鼠巨噬细胞内的 NO 检测.

在国外, Sessler 等 ${ }^{[102]}$ 利用苯并咪唑衍生物、吲哚和 TFA 在 1-(3-二甲氨基丙基)-3-乙基碳二亚胺盐(EDC)作 用的三组分反应，合成了可应用于检测 $\mathrm{CO}_{2}$ 的化学传感 器 107 (Scheme 26). 在乙腈溶液中, 高苂光性能的 107 可由 $\mathrm{F}^{-}$去质子化后形成无苂光性能的 $107-\mathrm{F}^{-}$化合物. 继续往溶液中通入 $\mathrm{CO}_{2}$ 气体后, 其苂光恢复, 溶液颜色 在紫外灯下可看到发生明显的变化, 而通入空气中其他 气体(如 $\mathrm{O}_{2} 、 \mathrm{~N}_{2}$ ) 等气体则无此现象, 故能实现 $\mathrm{CO}_{2}$ 的选 择性检测，检测下限可达 $4.1 \times 10^{-7} \mathrm{~mol} / \mathrm{L}$.
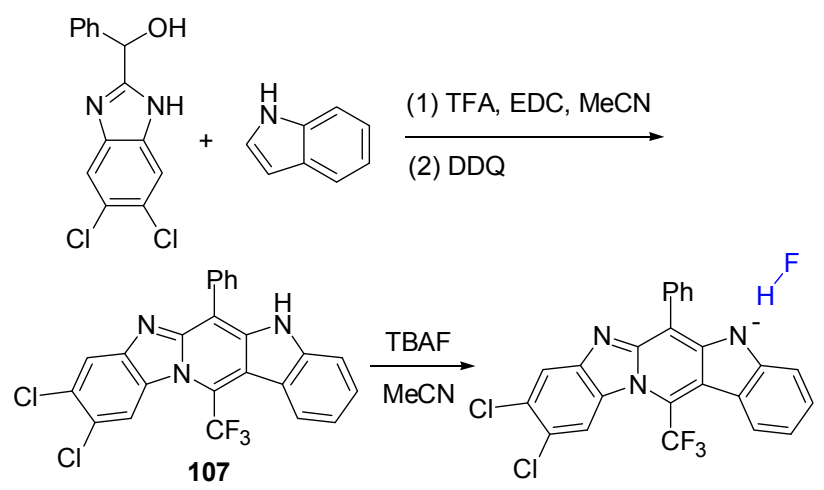

图式 26 传感器 107 的合成与作用机理

Scheme 26 Synthesis of sensor $\mathbf{1 0 7}$ and its interaction mechanism

除无机氧化物气体分子外，近年来也有苯并咪唑类 传感器应用于纳米金属氧化物半导体检测的报道. 例 
如, Jayabharathi 等 ${ }^{[103]}$ 报道了利用苯甲醛与邻苯二胺缩 合, 设计合成了化学传感器 108 (Eq. 35). 在 108 的溶液 中, 加入 $\mathrm{ZnO}$ 纳米粒子后, 108 被吸附在 $\mathrm{ZnO}$ 纳米粒子 的表面, 影响了其 PET 过程, 导致 108 在 $270 \mathrm{~nm}$ 处的紫 外吸收峰明显增强, 且在 $360 \mathrm{~nm}$ 的苂光发射峰显著增 强.<smiles>[Z10]CC(N)=O</smiles><smiles>c1ccc(Cn2c(-c3ccccc3)nc3ccccc32)cc1</smiles>

类似地, Jayabharathi 等 ${ }^{[104,105]}$ 还报道, 利用 $N$-取代 邻苯二胺与对氟苯甲醛缩合, 可合成了化学传感器 109 (Eq. 36), 109 也能被吸附在 $\mathrm{TiO}_{2} 、 \mathrm{WO}_{3} 、 \mathrm{CuO}$ 和 $\mathrm{Fe}_{2} \mathrm{O}_{3}$ 等纳米粒子的表面导致其光学性质的改变, 故可实现这 些纳米粒子的检测.<smiles>CCOC(C)(C)[N+](N)=O</smiles>

\section{4 应用于有机分子的检测}

与上述无机物的检测相比, 苯并咪唑基传感器应用 于有机物的检测相对较少, 但近来也开始引起关注, 其 中报道较多的是硝基芳香爆炸物, 如三硝基甲苯(TNT)、 苦味酸(PA)等. 例如, $\mathrm{Su}$ 等 ${ }^{[106]}$ 利用 $N$-烷基取代的 2-苯基
苯并咪唑和其他含氮配体与金属铱配位，构建了可应用 于 PA 检测的菼光化学传感器.

杯芳烃修饰的苯并咪唑传感器除可应用于金属离 子的检测外 ${ }^{[45]}$ ，也可应用于硝基爆炸物的检测，如传感 器 110 (Scheme 27). 在 THF 溶液中, 加入不同的爆炸物 分子，发现 TNT 与 110 以 $3: 1$ 发生络合，导致 110 的 苂光猝灭. 但是, 其他爆炸物(如黑索金和季戊四醇四硝 酸酯), 则对 110 苂光的影响程度远不及 TNT. 因此, 110 能实现 TNT 的选择性检测，检测下限可达 $3.05 \mu \mathrm{mol} / \mathrm{L}$. 值得注意的是，110 不仅能在溶液中检测 TNT，还能用 于 TNT 的固态检测, 因此可设计出用于固态检测 TNT 的压阻悬臂梁式传感器 ${ }^{[107]}$.

本课题组 ${ }^{[10]}$ 在苯并咪唑类苂光材料研究的基础上, 先利用均苯三甲酸和邻苯二胺类化合物在 PPA 催化下 进行缩合，再引进长烷基链来改善分子的溶解性并防止 分子聚集而导致荧光猝灭，设计合成了含有三个苯并咪 唑基的苂光探针 111 (Scheme 28). 在 THF 溶液中, 加入 的 PA 能与 111 发生 FRET, 导致 111 苂光淬灭, 而加入 相同量的其他硝基爆炸物(如 TNT、DNP 等)对 111 的荧 光猝灭程度远不及 PA, 故 111 能实现 PA 的选择性检测, 检测下限可达 $50 \mu \mathrm{g} / \mathrm{L}$. 值得注意的是, 111 不仅能在溶 液上检测 PA，还能在 TLC 板上或 Whatman 滤纸上实现 PA 的固态可视化检测，可望应用于 PA 固态检测的传感 器 ${ }^{[108]}$.

除了硝基芳香爆炸物的检测外，也有一些关于苯并 咪唑类传感器用于其他有机小分子(如 DMF、有机磺酸 等)的检测报道. 例如, Yesilel 等 ${ }^{[109]}$ 设计了苯并咪唑基

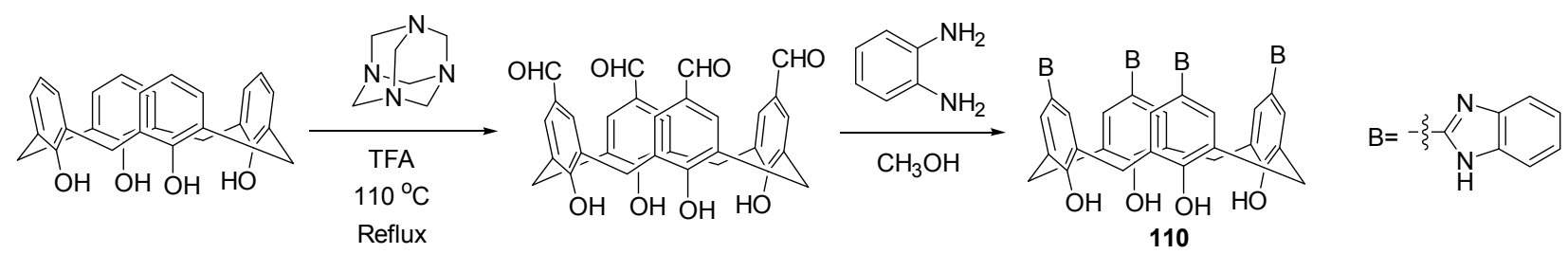

图式 27 传感器 $\mathbf{1 1 0}$ 的合成

Scheme 27 Synthesis of sensor 110

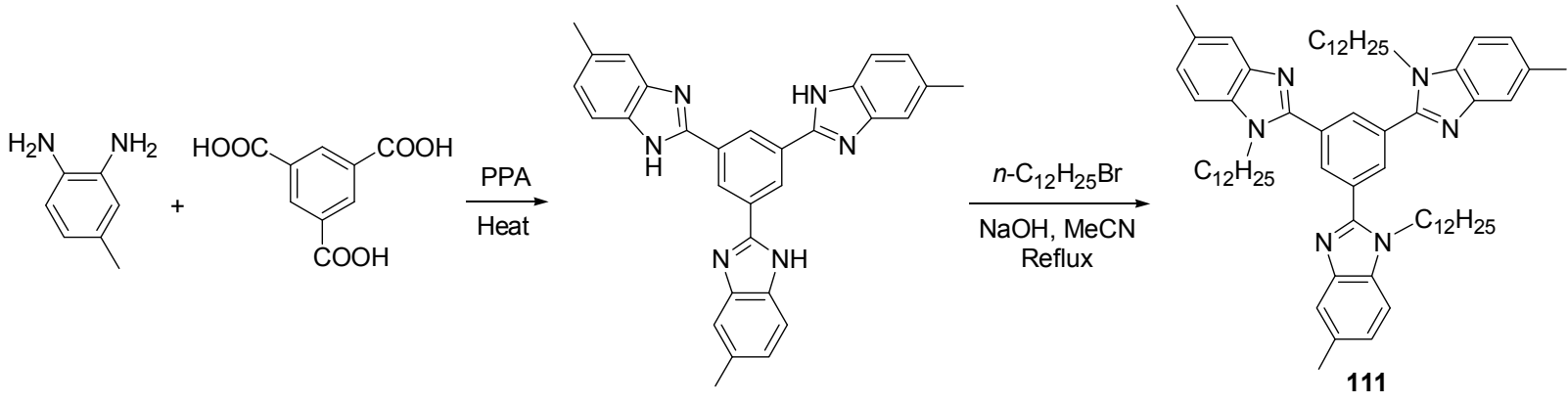

图式 28 荧光探针 111 的合成

Scheme 28 Synthesis of fluorescent probe $\mathbf{1 1 1}$ 
铜配位物传感器, 往其 $\mathrm{CH}_{3} \mathrm{OH}$ 溶液中滴加各种常用溶 剂, 只有滴加 DMF 时, 溶液由蓝色变为绿色, 故可通过 颜色变化来实现 DMF 的选择性检测.

Ghosh 等 ${ }^{[110]}$ 利用 9-氯甲基葱对 2-氨基苯并咪唑 43 进行 $N$-烷基化得到化合物 112, 再将荧光团通过酰胺基 连接到芳基二酰卤类受体上，设计合成了基于 PET 机理 的传感器 113 (Scheme 29). 在 $\mathrm{CHCl}_{3}$ 溶液中, 加入各种 有机酸类, 发现有机磺酸(如甲磺酸、对甲苯磺酸等)能 诱导 113 发生质子化, 影响其 PET 过程, 使 113 的荧光 猝灭, 而其他有机酸(如乙酸、三氟乙酸等)对 113 的苂 光的影响程度不及有机磺酸类, 故能在有机酸类中实现 有机磺酸的检测.

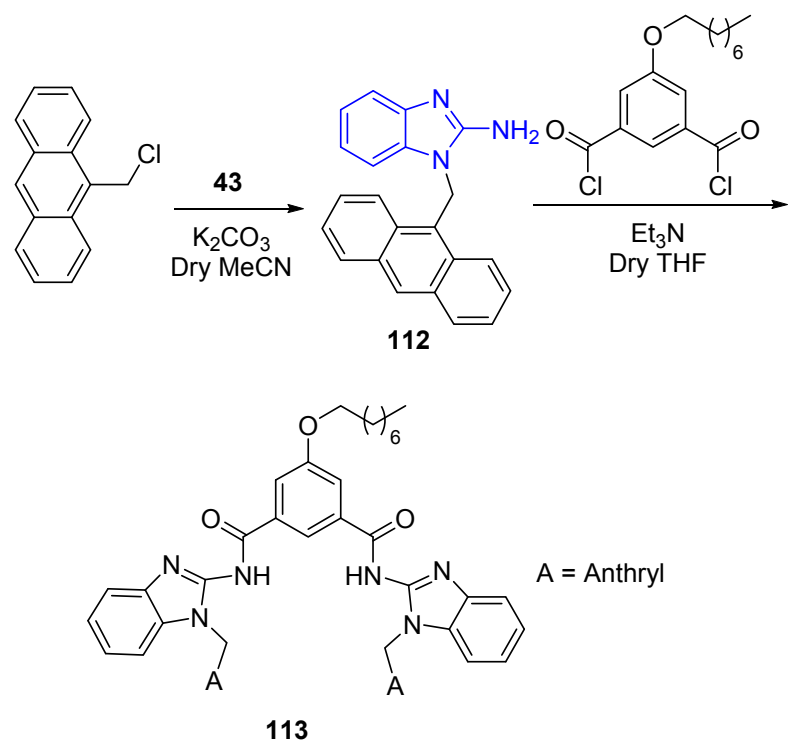

图式 29 传感器 113 的合成

Scheme 29 Synthesis of sensor 113

化合物 77 除可应用于 $\mathrm{Al}^{3+}$ 的检测外 ${ }^{[65]}$, 也可利用 其与 $\mathrm{Cu}^{2+}$ 配位后形成 77- $\mathrm{Cu}^{2+}$ 配合物而应用于有机小分 子草酸的检测. 在 $77-\mathrm{Cu}^{2+}$ 配合物的 $\mathrm{CH}_{3} \mathrm{OH} / \mathrm{H}_{2} \mathrm{O}$ 溶液 中, 加入草酸后, $\mathrm{Cu}^{2+}$ 从 77- $\mathrm{Cu}^{2+}$ 配合物中脱离出来, 导 致其在紫外吸收从原 $415 \mathrm{~nm}$ 处蓝移至 $375 \mathrm{~nm}$ 处, 而加 入其他二羊酸或阴离子则无影响, 故 $77-\mathrm{Cu}^{2+}$ 配合物可 实现草酸的选择性检测，检测下限可达 $70.8 \mu \mathrm{mol} / \mathrm{L}^{[111]}$.

近年来, 也有相关苯并咪唑类传感器应用于生物活 性分子检测的文献报道 ${ }^{[112]}$. 例如, Mathur 等 ${ }^{[113]}$ 利用苯 并咪唑类化合物 114 (图 5)与金属铜配位后应用于多巴 胺的检测; Ghosh 等 ${ }^{[114]}$ 利用苯并咪唑基传感器 115 可从 三磷酸腺苷(ATP)、二磷酸腺苷(ADP) 和单磷酸腺苷 (AMP)中选择识别出 ATP, 且 115 能穿过 HeLa 细胞膜 实现生物体内检测 ATP.

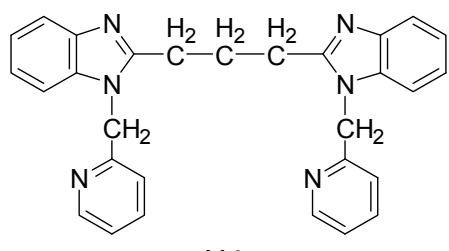

114

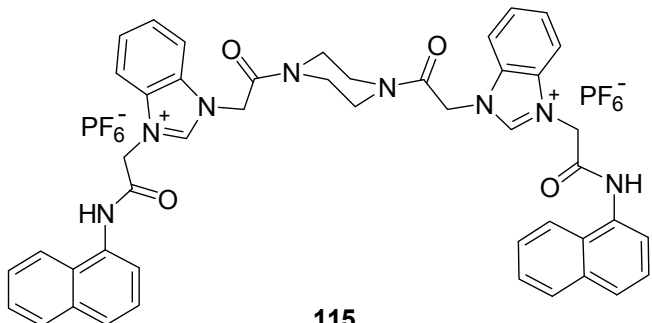

115

图 5 传感器 114 和 115 的结构式

Figure 5 Structures of chemosensors 114 and 115

\section{5 应用于 $\mathrm{pH}$ 的检测}

苯并咪唑类传感器在 $\mathrm{pH}$ 检测方面的应用, 近年来 也引起关注 ${ }^{[115]}$. 例如, Tolpygin 等 ${ }^{[16]}$ 利用化合物 $\mathbf{1 1 2}$ 上 氨基与 2-吡啶甲醛反应, 得到了可用于检测 $\mathrm{H}^{+}$的化学 传感器 116 (Eq. 37). 在乙腈溶液, 加入 $\mathrm{H}^{+}$后, 116 的 PET 过程终止，使得 116 原在 $760 \mathrm{~nm}$ 处的苂光增强，其 他离子(如金属离子)对 116 的荧光影响程度远不及 $\mathrm{H}^{+}$. 因此，化合物 116 能够选择性检测 $\mathrm{H}^{+}$而被设计成为检测 $\mathrm{pH}$ 的传感器.
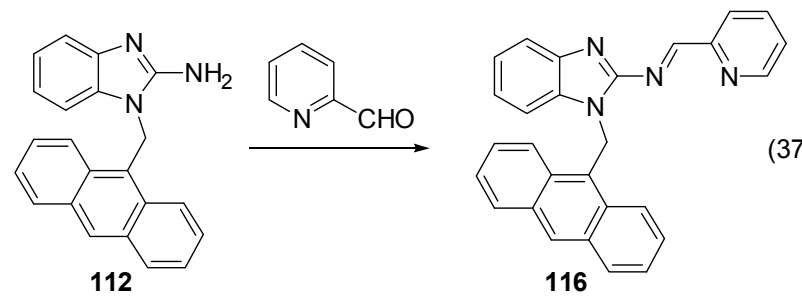

基于 ESIPT 的机理, Chan 等 ${ }^{[117]}$ 将苯并咪唑基连接 到螺吡喃上，也设计合成了可用于 $\mathrm{pH}$ 检测的传感器 $\mathbf{1 1 7}$ (Scheme 30). 在中性条件下 $\mathbf{1 1 7}$ 在 $517 \mathrm{~nm}$ 处有一个苂光 发射峰, 当加入酸性物质使 $\mathrm{pH}$ 下降时, 117 中的螺吡喃 发生开环, 构型发生变化, 影响其 ESIPT 过程, 导致 117 在原 $517 \mathrm{~nm}$ 处的苂光减弱, 并在 $690 \mathrm{~nm}$ 处的苂光增强, 特别是当 $\mathrm{pH}=5.5$ 时, 117 在 $690 \mathrm{~nm}$ 处的苂光达到最大. 因此，可利用 $690 \mathrm{~nm}$ 处与 $517 \mathrm{~nm}$ 处的荧光强度比值变 化, 设计出用于检测 $\mathrm{pH}$ (5.5 7.0 范围处)的传感器.

由于许多生物代谢过程在酸性条件下进行, 故设计 可用于体内检测 $\mathrm{pH}$ 的传感器更是意义重大. Kim 等 ${ }^{[118]}$ 在这方面做了重要的贡献，他报道了系列可用于体内检 测 $\mathrm{pH}$ 的双光子苯并咪唑类传感器 118、119 (Scheme 31). 
<smiles>CC(C)(C)c1ccc(O)cc1</smiles>

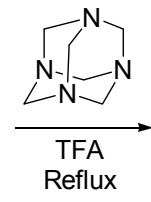<smiles>CC(C)(C)c1cc(C=O)c(O)c(C=O)c1</smiles>

(1)<smiles>Nc1ccccc1N</smiles>
EtOH, reflux (2) $\mathrm{DDQ}, \mathrm{CH}_{2} \mathrm{Cl}_{2}$<smiles>CC(C)(C)c1cc(C=O)c(O)c(-c2nc3ccccc3[nH]2)c1</smiles>
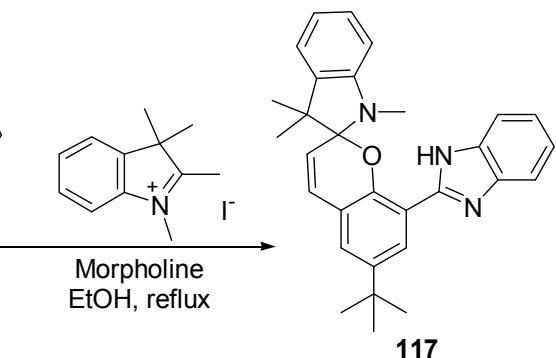

图式 30 传感器 117 的合成

Scheme 30 Synthesis of sensor 117

在缓冲溶液中, 碱性或者中性条件下 118 的紫外吸收峰 和苂光发射峰一样, 而酸性条件下 118 的紫外吸收峰和 苂光发射峰发生了明显的变化, 且苂光颜色由蓝色变为 绿色. 这是由于在酸性条件下 118 发生了质子化, 导致 ICT 过程加强, 故 118 能够实现 $\mathrm{pH}$ 的检测. 118 无细胞 毒性, 能够在 HeLa 细胞和小鼠脑组织中实现 $\mathrm{pH}$ 值的测 定. 传感器 119 具有与 118 类似的性质, 但特别的是, 119 能够对体内溶酶体有靶向作用, 可实现细胞中溶酶 体 $\mathrm{pH}$ 的测定.<smiles>[R]c1cc(N)c([R])cc1N</smiles><smiles>COC(=O)CN(C)c1ccc2cc(C=O)ccc2c1</smiles>

图式 31 传感器 118 和 119 的合成 Scheme 31 Synthesis of sensors 118 and 119

\section{6 结束语}

利用苯并咪唑类传感器对环境和生物体内各种物 质的检测，目前都得到了空前的发展，但是报道较多的 仍然以金属离子、阴离子为主，且大部分都是体外的检 测. 因此, 展望未来, 利用苯并咪唑基苂光化学传感器 检测其他物质，如无机物小分子、氧化物纳米粒子以及 有机分子等，尚待加强研究. 同时，鉴于苂光传感器在 生物体内检测 ${ }^{[119,120]}$ 的重要性, 加强苯并咪唑类传感器 的体内检测研究也很重要.

在设计合成方面，目前涉及的荧光检测机理很多， 如 ICT、ESIPT、PET ${ }^{[120,121]}$ 以及 FRET ${ }^{[46,108]}$ 等，因此根 据实际需要，巧妙利用这些机理设计合成出高选择性、 高灵敏度的苯并咪唑类传感器仍需要努力. 同时, 随着

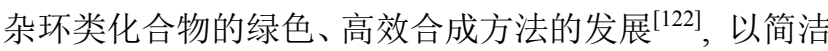
的合成方法得到理想的苯并咪唑基菼光传感器仍然是 一个充满活力的课题.

\section{References}

[1] Singh, S.; Bharti, N.; Mohapatra, P. P. Chem. Rev. 2009, 109, 1900.

[2] Marson, C. M. Chem. Rev. 2011, 111, 7121.

[3] Mao, Z.-Z.; Wang, Z.-Y.; Hou, X.-N.; Song, X.-M.; Luo, Y.-F. Chin. J. Org. Chem. 2008, 28, 542 (in Chinese). (毛郑州, 汪朝阳, 侯晓娜, 宋秀美, 罗玉芬, 有机化学, 2008, 28, 542.)

[4] Zhu, G.-M.; Yang, L.-Y.; Cui, D.-M. Chin. J. Org. Chem. 2014, 34, 495 (in Chinese.) (朱观明, 杨柳阳, 崔冬梅. 有机化学, 2014, 34, 495.)

[5] Peng, P.; Xiong, J.-F.; Li, B.; Mo, G.-Z.; Chen, R.-H.; Wang, Z.-Y Chin. J. Org. Chem. 2013, 33, 1891 (in Chinese).

(彭湃，熊金锋，李豹，莫广珍，陈任宏，汪朝阳，有机化学， 2013, 33, 1891.)

[6] Li, Y.; Ma, H.-Q.; Wang, Y.-L. Chin. J. Org. Chem. 2008, 28, 210 (in Chinese). (李炎, 马会强, 王玉炉, 有机化学, 2008, 28, 210.)

[7] Mao, Z.-Z.; Li, J.-X.; Xue, F.-L.; Chen, R.-H.; Wang, Z.-Y. Chem. Res. Appl. 2012, 24, 497 (in Chinese). (毛郑州, 李建晓, 薛福玲, 陈任宏, 汪朝阳, 化学研究与应用, 2012, 24, 497.)

[8] Xiong, J.-F.; Luo, S.-H.; Wang, Q.-F.; Wang, Z.-Y.; Qi, J. Des. Monomers Polym. 2013, 16, 389.

[9] Xiong, J.-F.; Wang,Q.-F.; Peng, P.; Shi, J.; Wang, Z.-Y.; Yang, C.-L. J. Appl. Polym. Sci. 2014, 131, 40275.

[10] Xiong, J.-F.; Luo, S.-H.; Huo, J.-P.; Liu, J.-Y.; Chen, S.-X.; Wang, Z.-Y.J. Org. Chem. 2014, 79, 8366.

[11] Tzeng, B. C.; Chen, B. S.; Chen, C. K.; Chang, Y. P.; Tzeng, W. C.; Lin, T. Y.; Lee, G. H.; Chou, P. T.; Fu, Y. J.; Chang, A. H. H. Inorg. Chem. 2011, 50, 5379.

[12] Yu, H.; Wang, S.; Son, Y. A. Mol. Cryst. Liq. Cryst. 2012, 568, 117.

[13] Zhong, K.-L.; Zhou, X.; Hou, R.-B.; Zhou, P.; Hou, S.-H.; Bian, Y.-J.; Zhang, G.; Tang, L.-J.; Shang, X.-H. RSC Adv. 2014, 4, 16612.

[14] Hu, J.-H.; Li, J.-B.; Qi, J.; Chen, J.-J. New J. Chem. 2015, 39, 843.

[15] Yang, Y.; Li, B.; Zhang, L.-M.; Guan, Y.-L. J. Lumin. 2014, 145, 895. 
[16] Peng, P.; Xiong, J.-F.; Mo, G.-Z.; Zheng, J.-L.; Chen, R.-H.; Chen, X.-Y.; Wang, Z.-Y. Amino Acids 2014, 46, 2427.

[17] Chen, R.-H.; Xiong, J.-F.; Peng, P.; Mo, G.-Z.; Tang, X.-S.; Wang, Z.-Y.; Wang X.-F. Asian J. Chem. 2014, 26, 926.

[18] Ghosh, K.; Sarkar, T. Supramol. Chem. 2012, 24, 748.

[19] Madhu, S.; Sharma, D. K.; Basu, S. K.; Jadhav, S.; Chowdhury, A.; Ravikanth, M. Inorg. Chem. 2013, 52, 11136.

[20] Wang, Q.-M.; Tan, C.-L. Anal. Chim. Acta 2011, 708, 111.

[21] Kim, S. J.; Kool, E. T. J. Am. Chem. Soc. 2006, 128, 6164.

[22] Jayabharathi, J.; Thanikachalam, V.; Jayamoorthy, K.; Sathishkumar, R. Spectrochim. Acta, Part A 2012, 97, 384.

[23] Cimen, O. Z; Dincalp, H.; Varlikli, C. Sens. Actuators B 2015, 209, 853.

[24] Li, J.-B.; Hu, Q.-H.; Yu, X.-L.; Zeng, Y.; Cao, C.-C.; Liu, X.-W.; Guo, J.; Pan, Z.-Q. J. Fluoresc. 2011, 21, 2005.

[25] Zhang, Y.; Wang, J.-M.; Shu, W.-H.; Chen, Q.; Ma, Z.-G.; Chen, X.-M. Chin. J. Inorg. Chem. 2013, 29, 150 (in Chinese). (张勇, 王继猛, 舒威虎, 陈其, 马志刚, 陈雪梅. 无机化学学报, 2013, 29, 150.)

[26] Liu, J.; Lin, Q.; Zhang, Y.-M.; Wei, T.-B. Sci. China Chem. 2014, 57, 1257.

[27] Wang, M.; Wang, J.-G.; Xue, W.-J.; Wu, A.-X. Dyes Pigm. 2013, $97,475$.

[28] Jung, H. J.; Singh, N.; Jang, D. O. Tetrahedron Lett. 2008, 49, 2960.

[29] Lee, D. Y.; Singh, N.; Jang, D. O. Tetrahedron Lett. 2010, 51, 1103.

[30] Lu, L.-J.; Yin, M.-C.; Fan, Y-T.; Hou, H.-W.; Wu, Y.-J. Chin. J. Inorg. Chem. 2001, 17, 478 (in Chinese). (卢会杰, 尹明彩, 樊耀亭, 侯红卫, 吴养洁, 无机化学学报, 2001, 17, 478.)

[31] Lee, D. Y.; Singh, N.; Jang, D. O. Tetrahedron Lett. 2011, 52, 1368.

[32] Lee, D. Y.; Singh, N.; Jang, D. O. Tetrahedron Lett. 2011, 52, 3886 .

[33] Tang, L. J.; Zhou, P.; Zhong, K. L.; Hou, S. H. Sens. Actuators, B 2013, 182, 439.

[34] Tang, L. J.; Wang, N. N.; Zhang, Q.; Guo, J. J.; Nandhakumar, R. Tetrahedron Lett. 2013, 54, 536.

[35] Saluja, P.; Kaur, N.; Singh, N.; Jang, D. O. Tetrahedron Lett. 2012, $53,3292$.

[36] Tang, L.-J.; Cai, M.-J. Sens. Actuators B 2012, 173, 862.

[37] Wang, X.-J.; Xu, T.; Duan, H.-D. Sens. Actuators B 2015, 214, 138.

[38] Tang, L.-J.; Dai, X.; Cai, M.-J.; Zhao, J.; Zhou, P.; Huang, Z.-L. Spectrochim. Acta, Part A 2014, 122, 656.

[39] Mahiya, K.; Mathur, P. J. Fluoresc. 2013, 23, 767.

[40] Mahiya, K.; Mathur, P. Spectrochim. Acta, Part A 2013, 113, 386.

[41] Ghosh, K.; Sarkar, T. Supramol. Chem. 2011, 23, 435.

[42] Tang, L.-J.; Li, F.-F.; Liu, M.-H.; Nandhakumar, R. Bull. Korean Chem. Soc. 2010, 31, 3212.

[43] Chipem, F. A. S.; Behera, S. K.; Krishnamoorthy, G. Sens. Actuators B 2014, 191, 727.

[44] Pandey, A. D.; Pissurlenkar, R. R. S.; Karnik, A. V. J. Inclusion Phenom. Macrocycl. Chem. 2015, 81,251.

[45] Pathak, R. K.; Hinge, V. K.; Mondal, P.; Rao, C. P. Dalton Trans. 2012, 41, 10652.

[46] Goswami, S.; Maity, S.; Maity, A. C.; Maity, A. K.; Das, A. K.; Saha, P. RSC Adv. 2014, 4, 6300.

[47] Lal, A. K.; Milton, M. D. Sens. Actuators B 2014, 202, 257.

[48] Jayabharathi, J.; Thanikachalam, V.; Jayamoorthy, K. Spectrochim. Acta, Part A 2012, 95, 143.

[49] El Majzoub, A.; Cadiou, C.; Dechamps-Olivier, I.; Chuburu, F.;
Aplincourt, M. Eur. J. Inorg. Chem. 2007, 5087.

[50] El Majzoub, A.; Cadiou, C.; Dechamps-Olivier, I.; Chuburu, F.; Aplincourt, M.; Tinant, B. Inorg. Chim. Acta 2009, 362, 1169.

[51] El Majzoub, A.; Cadiou, C.; Dechamps-Olivier, I.; Tinant, B.; Chuburu, F. Inorg. Chem. 2011, 50, 4029.

[52] Zhong, K.-L.; Cai, M.-J.; Hou, S.-H.; Bian, Y.-J.; Tang, L.-J. Bull. Korean Chem. Soc. 2014, 35, 489.

[53] Tang, L.-J.; Cai, M.-J.; Zhou, P.; Zhao, J.; Zhong, K.-L.; Hou, S.-H.; Bian, Y.-J. RSC Adv. 2013, 3, 16802.

[54] Tang, L.-J.; Cai, M.-J.; Zhou, P.; Zhao, J. ; Huang, Z.-L.; Zhong, K.-L.; Hou, S.-H.; Bian, Y.-J. J. Lumin. 2014, 147, 179.

[55] Martin, D.; Rouffet, M.; Cohen, S. M.. Inorg. Chem. 2010, 49, 10226.

[56] Henary, M. M.; Wu, Y.; Fahrni, C. J. Chem. Eur. J. 2004, 10, 3015.

[57] Henary, M. M.; Fahrni, C. J. J. Phys. Chem. A 2002, 106, 5210.

[58] Kim, M. J.; Kaur, K.; Singh, N.; Jang, D. O. Tetrahedron 2012, 68, 5429.

[59] Mashraqui, S. H.; Sundaram, S.; Khan, T. Chem. Lett. 2006, 135, 786.

[60] Lohar, S.; Karak, D.; Guha, S.; Banerjee, A.; Sahana, A.; Das, D. Spectrosc. Lett. 2013, 46, 28.

[61] Kumar, A.; Singh, A. K.; Gupta, T. Analyst 2013, 138, 3356.

[62] Velmurugan, K.; Raman, A;. Don, D.; Tang, L.-J.; Easwaramoorthi, S.; Nandhakuma, R. RSC Adv. 2015, 5, 44463.

[63] Cao, W.; Zheng, X.-J.; Sun, J.-P.; Wong, W.-T.; Fang, D.-C; Zhang, J.-X.; Jin, L.-P. Inorg. Chem. 2014, 53, 3012.

[64] Jeyanthi, D.; Iniya, M.; Krishnaveni, K.; Chellappa, D. RSC Adv. 2013, 3, 20984.

[65] Iniya, M.; Jeyanthi, D.; Krishnaveni, K.; Chellappa, D. J. Lumin. 2014, 157, 383.

[66] Ma, T.; Zhang, J.; Liu, L.-Z. He, Y.; Zhang, Z.-T. Chin. J. Org. Chem. 2014, 34, 1780 (in Chinese).

(马拓, 张瑾, 刘龙珠, 贺云, 张尊听, 有机化学, 2014, 34, 1780.)

[67] Alvaro, M.; Garcia, H.; Palomares, E.; Achour, R.; Moussaif, A.; Zniber, R. Chem. Phys. Lett. 2001, 350, 240.

[68] Saluja, P.; Sharma, H.; Kaur, N.; Singh, N.; Jang, D. O. Tetrahedron 2012, 68, 2289.

[69] Saluja, P.; Kaur, N.; Singh, N.; Jang, D. O. Tetrahedron 2012, 68, 8551.

[70] Alizadeh, A.; Khodaei, M. M.; Hamidi, Z. Sens. Actuators, B 2014, 190, 782 .

[71] Firooz, A. R.; Ensafi, A. A.; Kazemifard, N.; Sharghi, H. Talanta 2012, 101, 171.

[72] Dessingou, J.; Mitra, A.; Tabbasum, K.; Baghel, G. S.; Rao, C. P. J. Org. Chem. 2012, 77, 371.

[73] Li, G.; Gong, W.-T.; Ye, J.-W.; Lin, Y.-A.; Ning, G.-L. Tetrahedron Lett. 2011, 52, 1313.

[74] Pang, S.-T.; Zheng, Y.-H.; Zhou, Z.; Tan, C.-L.; Wang, Q.-M.; Li, X.-D. Opt. Mater. 2013, 35, 1157.

[75] Wang, J.-A.; Bai, F.-Q.; Xia, B.-H.; Sun, L.; Zhang, H.-X. J. Phys. Chem. A 2011, 115, 1985.

[76] Khanmohammadi, H.; Rezaeian, K. New J. Chem. 2014, 38, 5536.

[77] Chetia, B.; Iyer, P. K. Sens. Actuators, B 2014, 201, 191.

[78] Gupta, A. S.; Paul, K.; Luxami, V. Spectrochim. Acta, Part A 2015, $138,67$.

[79] Madhu, S.; Ravikanth, M. Inorg. Chem. 2014, 53, 1646.

[80] Bren, V. A.; Tolpygin, I. E.; Tikhomirova, K. S.; Popova, O. S.; Bren, Z. V.; Revinskii, Y. V.; Dubonosov, A. D.; Minkin, V. I. Chem. Heterocycl. Compd. 2014, 50, 1665.

[81] Moon, K. S.; Singh, N.; Lee, G. W.; Jang, D. O. Tetrahedron 2007, $63,9106$.

[82] Shao, J.; Qiao, Y.-H.; Lin, H.; Lin, H.-K. J. Fluoresc. 2009, 19, 
183.

[83] Yang, X.-F.; Qi, H.-P.; Wang, L.-P.; Su, Z.; Wang, G. Talanta 2009, 80, 92.

[84] Kaur, N.; Dhaka, G.; Singh, J. Tetrahedron Lett. 2015, 56, 1162.

[85] Sharma, H.; Guadalupe, H. J.; Narayanan, J.; Hofeld, H.; Pandiyan, T. Singh, N. Anal. Methods 2013, 5, 3880.

[86] Sharma, H.; Bhardwaj, V. K.; Kaur, N.; Singh, N.; Jang, D. O. Tetrahedron Lett. 2013, 54, 5967.

[87] Lee, D. Y.; Singh, N.; Kim, M. J.; Jang, D. O. Org. Lett. 2011, 13, 3024.

[88] Mahapatra, A. K.; Maiti, K.; Manna, S. K.; Maji, R.; Das M. C.; Pakhira, B.; Sarkar, S. Chem. Asian J. 2014, 9, 3623.

[89] Zelder, F. H. Inorg. Chem. 2008, 47, 1264.

[90] Li, J.-B.; Hu, J.-H.; Chen, J.-J.; Qi, J. Spectrochim. Acta, Part A 2014, 133, 773.

[91] Guo, Y.-Y.; Tang, X.-L.; Hou, F.-P.; Wu, J.; Dou, W.; Qin, W.-W.; Ru, J.-X.; Zhang, G.-L.; Liu, W.-S.; Yao, X.-J. Sens. Actuators $B$ 2013, 181, 202.

[92] Chetia, B.; Iyer, P. K. Spectrochim. Acta, Part A 2011, 81, 313.

[93] Mukherjee, M.; Pal, S.; Sen, B.; Lohar, S.; Banerjee, S.; Banerjee, S.; Chattopadhyay, P. RSC Adv. 2014, 4, 27665.

[94] Wang, G.; Qi, H.-P.; Yang, X.-F. Luminescence 2013, 28, 97.

[95] Das, S.; Banerjee, A.; Lohar, S.; Sarkar, B.; Mukhopadhyay, S. K.; Matalobos, J. S.; Sahana, A.; Das, D. New J. Chem. 2014, 38, 2744.

[96] Kar, C.; Das, G. J. Photochem. Photobiol., A 2013, 251, 128.

[97] Sun, M.-T.; Yu, H.; Li, H.-H.; Xu, H.-D.; Huang, D.-J.; Wang, S.-H. Inorg. Chem. 2015, 54, 3766.

[98] Choi, H. W.; Kim, Y. S.; Yang, N. C.; Suh, D. H. J. Appl. Polym. Sci. 2004, $91,90$.

[99] Saikia, G.; Iyer, P. K. Macromolecules 2011, 44, 3753.

[100] Lirag, R. C.; Le, H. T. M.; Miljanic, O. S. Chem. Commun. 2013, 49, 4304.

[101] Zhao, Y; Gao, F.-B; Wu, K; Shen, C; Hong, H; Wang, X.-Y; Chen, J.-N; Mang, J.-F. Chin. J. Inorg. Chem. 2009, 25, 1513 (in Chinese).

(赵勇, 高凤博, 吴可, 沈超, 洪浩, 王晓勇, 洪浩, 陈江宁, 张峻 峰, 无机化学学报, 2009, 25, 1513.)

[102] Ishida, M.; Kim, P.; Choi, J.; Yoon, J.; Kim, D.; Sessler, J. L. Chem. Commun. 2013, 49, 6950.
[103] Karunakaran, C.; Jayabharathi, J.; Jayamoorthy, K.; Vinayagamoorthy, P. J. Photochem. Photobiol., A 2012, 247, 16.

[104] Karunakaran, C.; Jayabharathi, J.; Jayamoorthy, K. Sens. Actuators B 2013, 188, 207.

[105] Karunakaran, C.; Jayabharathi, J.; Jayamoorthy, K. Sens. Actuators $B$ 2013, $182,514$.

[106] Han, Y.; Cao, H.-T.; Sun, H.-Z.; Shan, G.-G.; Wu, Y.; Su, Z.-M.; Liao, Y. J. Mater. Chem. C 2015, 3, 2341.

[107] Kandpal, M.; Bandela, A. K.; Hinge, V. K.; Rao, V. R.; Rao, C. P. ACS Appl. Mater. Interfaces 2013, 5, 13448.

[108] Xiong, J.-F.; Luo, S.-H.; Huo, J.-P.; Liu, J.-Y.; Chen, S.-X.; Wang, Z.-Y. J. Org. Chem. 2014, 79, 11619.

[109] Arici, M.; Yesilel, O. Z.; Tas, M. Dalton Trans. 2015, 44, 1627.

[110] Ghosh, K.; Sen, T.; Patra, A. New J. Chem. 2010, 34, 1387.

[111] Saluja, P.; Kaur, N.; Kang, J.; Singh, N.; Jang, D. O. Tetrahedron 2013, 69, 9001.

[112] Dai, M.; Zhu, W.-P.; Xu, Y.-F.; Qian, X.-H.; Liu, Y.; Xiao, Y.; You, Y. J Fluoresc. 2008, 18, 591.

[113] Khattar, R.; Mathur, P. Inorg. Chem. Commun. 2013, 31, 37.

[114] Ghosh, K.; Tarafdar, D.; Samadder, A.; Khuda-Bukhsh, A. R. RSC Adv. 2014, 4, 58530 .

[115] Saeed, M. A.; Le, H. T. M.; Miljanic, O. S. Acc. Chem. Res. 2014, 47, 2074.

[116] Tolpygin, I. E.; Revinskii, Y. V.; Starikov, A. G.; Dubonosov, A. D.; Bren, V. A.; Minkin, V. I. Chem. Heterocycl. Compd. 2013, 47, 1230.

[117] You, Q.-H.; Fan, L.; Chan, W.-H.; Lee, A. W. M.; Shuang, S.-M. RSC Adv. 2013, 3, 15762.

[118] Kim, H. J.; Heo, C. H.; Kim, H. M. J. Am. Chem. Soc. 2013, 135, 17969.

[119] Ashton T. D.; Jolliffe K. A.; Pfeffer F. M. Chem. Soc. Rev. 2015, $44,4547$.

[120] Vendrell, M.; Zhai, D. T.; Er, J. C.; Chang, Y. T. Chem. Rev. 2012, 112, 4391.

[121] Daly, B.; Ling, J.; de Silva, A. P. C Chem. Soc. Rev. 2015, 44, 4203.

[122] Guo, X.-X.; Gu, D.-W.; Wu, Z.-X.; Zhang, W.-B. Chem. Rev. 2015, 115,1622

(Cheng, F.) 